NOTICE: this is the author's version of a work that was accepted for publication in Journal of Materials Chemistry A. Changes resulting from the publishing process, such as peer review, editing, corrections, structural formatting, and other quality control mechanisms may not be reflected in this document. Changes may have been made to this work since it was submitted for publication. A definitive version was subsequently published in Journal of Materials Chemistry A 2 (2014) 18624; DOI: 10.1039/C4TA03225J. 


\title{
Oxide ion distribution, vacancy ordering and electrical behaviour in the $\mathrm{Bi}_{3} \mathrm{NbO}_{7}-\mathrm{Bi}_{3} \mathrm{YbO}_{6}$ pseudo binary system.
}

\author{
M. Leszczynska, ${ }^{a}$ X. Liu, ${ }^{b}$ W. Wrobel, ${ }^{a}$ M. Malys, ${ }^{a}$ J.R. Dygas, ${ }^{a}$ S. T. Norberg, ${ }^{c}$ S. Hull, ${ }^{d}$ \\ F. $\operatorname{Krok}^{a^{*}}$ and I. Abrahams ${ }^{b^{*}}$
}

Oxide ion distribution, vacancy ordering and electrical conductivity has been examined in the $\mathrm{Nb} / \mathrm{Yb}$ double substituted bismuth oxide based system $\mathrm{Bi}_{3} \mathrm{Nb}_{1-x} \mathrm{Yb}_{x} \mathrm{O}_{7-x}$, using $\mathrm{X}$-ray and neutron powder diffraction, reverse Monte Carlo modelling of total neutron scattering data and a.c. impedance spectroscopy. Transference number measurements confirm the system to be predominantly ionically conducting above $c a .450^{\circ} \mathrm{C}$. Niobium rich compositions show incommensurate ordering of the fluorite subcell, while increasing ytterbium content results in a commensurate fluorite, with fully disordered cation and anion sublattices. Oxide ion distribution shows both compositional and thermal dependencies. The latter is discussed with respect to its effect on the thermal variation of cubic lattice parameter. Substitution of bismuth by niobium and ytterbium in the cation sublattice of bismuth oxide leads to the creation of Frenkel interstitial oxide ions, which increase the tetrahedral vacancy concentration. The high vacancy concentration is confirmed in both Rietveld and RMC analyses of neutron data. Examination of vacancy ordering, in the $x=0.6$ composition, indicates a favouring of $\langle 100\rangle$ vacancy pair alignment.

\section{Keywords:}

Bismuth oxide; bismuth niobium ytterbium oxide; fluorite structure, defect structure; neutron diffraction; total scattering; reverse Monte Carlo modelling; X-ray diffraction; a.c. impedance spectroscopy. 


\section{Introduction}

There has been much focus in recent years in lowering the operating temperatures of solid oxide fuel cells (SOFCs) to the intermediate temperature region, ca. 500 to $700{ }^{\circ} \mathrm{C}$. Arguably, the electrolyte is the key component of such devices since its properties dictate the choice of the other components. Bismuth oxide based solid electrolytes have been studied for many years because of their exceptional oxide ion conductivities at significantly lower temperatures than traditional electrolytes, such as the stabilised zirconias. However, the practical application of bismuth oxide based electrolytes in SOFCs has been limited due to phase instability at operational temperatures, as well as the reduction of bismuth at low oxygen partial pressures. The first problem can be overcome through proper doping of materials to yield stable compounds ${ }^{1-4}$ and recently, it has been shown that by appropriate design of devices, bismuth oxide based materials have real potential in SOFC applications. ${ }^{5,6}$ Much research has been carried out on stabilisation of the highly conducting $\delta$-phase of $\mathrm{Bi}_{2} \mathrm{O}_{3}$, which is only stable at temperatures above $c a .730^{\circ} \mathrm{C}^{7}$ Substitution of bismuth by isovalent or aliovalent cations can lead to a variety of fluorite based structures, some of which show high oxide ion conductivity. ${ }^{8-13}$

The $\mathrm{Bi}_{2} \mathrm{O}_{3}-\mathrm{Nb}_{2} \mathrm{O}_{5}$ system has been extensively studied ${ }^{14-20}$ and exhibits a number of ordered fluorite phases depending on $\mathrm{Nb}_{2} \mathrm{O}_{5}$ content, as well as the synthesis conditions. At the $3: 1 \mathrm{Bi}: \mathrm{Nb}$ ratio, samples show unusual polymorphism, with a pseudo-cubic phase (designated type II) present at temperatures up to $\mathrm{ca} .800^{\circ} \mathrm{C}$ and above $900^{\circ} \mathrm{C}$, while between these temperatures a tetragonally ordered fluorite phase is seen (designated type III). ${ }^{19,20}$ At room temperature, the type II phase shows a three dimensional incommensurate modulation, with weak superlattice peaks clearly evident in neutron and electron diffraction patterns. ${ }^{21,22}$ The incommensurate structure of the type II phase has recently been resolved to reveal chains of distorted trigonal anti-prisms, with pyrochlorelike regions at the chain intersections. ${ }^{23}$

Rare earth substitution for bismuth in $\mathrm{Bi}_{2} \mathrm{O}_{3}$ readily yields $\delta-\mathrm{Bi}_{2} \mathrm{O}_{3}$ face centred cubic (fcc) type phases, as well as a number of other fluorite related structures. ${ }^{11}$ Ytterbium substitution in $\delta$ $\mathrm{Bi}_{2} \mathrm{O}_{3}$ has been well studied, with significant discrepancies in the literature concerning the appearance or non-appearance of the fcc phase. ${ }^{24-30}$ In the most recent study by Drache et al., ${ }^{27}$ the equilibrium phase diagram for the $\mathrm{Bi}_{2} \mathrm{O}_{3}-\mathrm{Yb}_{2} \mathrm{O}_{3}$ system was presented and for compositions with $\mathrm{Bi}: \mathrm{M}$ ratios close to $3: 1$, as in the present study, the fcc phase is only stable at temperatures above $800^{\circ} \mathrm{C}$. Below this temperature, a mixture of orthorhombic $\mathrm{Bi}_{17} \mathrm{Yb}_{7} \mathrm{O}_{36}$, and triclinic $\mathrm{BiYbO}_{3}$ is the

stable state. Nevertheless, the $\delta$-phase is readily quenchable at $25 \%$ substitution, ${ }^{28-30}$ but on prolonged annealing at $500^{\circ} \mathrm{C}$, exhibits the highest conductivity decay of all the rare earth 
substituted phases. This has been associated with redistribution of the oxide ions leading to vacancy ordering. Studies by Battle et $a .^{31}$ on the bismuth ytterbate system revealed short-range vacancy/anion ordering, which manifested itself as rhombohedral microdomains. The conduction pathways in $\delta-\mathrm{Bi}_{1.4} \mathrm{Yb}_{0.6} \mathrm{O}_{3}$ have been studied by maximum entropy methods combined with Rietveld analysis ${ }^{32}$ and reveal an oxide ion conduction pathway in the $\langle 100\rangle$ direction, as well as a shift of the oxide ions away from the ideal tetrahedral site in the $\langle 111\rangle$ direction. In our own recent studies on the $\mathrm{Bi}_{2} \mathrm{O}_{3}-\mathrm{Yb}_{2} \mathrm{O}_{3}$ system, using reverse Monte Carlo (RMC) modelling of total neutron scattering data, favouring of $\langle 100\rangle$ vacancy ordering was observed. ${ }^{33,34}$

A number of studies have examined co-doping of bismuth oxide, which has been observed to have the advantage of stabilising the cubic $\delta$-phase at lower levels of substitution than singledoping. ${ }^{35}$ This has been explained in terms of an increased configurational entropy contribution. The combination of isovalent and aliovalent dopants allows for modification of the vacancy concentration and hence oxide ion conductivity. We have previously examined this effect in the analogous pseudo-binary systems $\mathrm{Bi}_{3} \mathrm{YO}_{6}-\mathrm{Bi}_{3} \mathrm{NbO}_{7}{ }^{36}$ and $\mathrm{Bi}_{3} \mathrm{ErO}_{6}-\mathrm{Bi}_{3} \mathrm{NbO}_{7}{ }^{37}$ and found compositional, as well as thermal, dependencies of the oxide ion distributions in these systems. In the present study, we examine the compositional and thermal dependence of defect structure and electrical conductivity in the pseudo-binary system $\mathrm{Bi}_{3} \mathrm{YbO}_{6}-\mathrm{Bi}_{3} \mathrm{NbO}_{7}$. $\mathrm{RMC}$ modelling of total neutron scattering data is used to examine short-range vacancy ordering in this system. Additionally, the high neutron contrast afforded by $\mathrm{Yb}$ in this system allows for discrimination of the individual cation coordination environments using the RMC approach.

\section{Experimental}

\section{Sample preparations}

Samples of general composition $\mathrm{Bi}_{3} \mathrm{Nb}_{1-x} \mathrm{Yb}_{x} \mathrm{O}_{7-x}(0.2 \leq x \leq 0.8)$ were prepared using stoichiometric amounts of $\mathrm{Bi}_{2} \mathrm{O}_{3}$ (Sigma Aldrich, 99.9\%), $\mathrm{Nb}_{2} \mathrm{O}_{5}$ (Sigma Aldrich, 99.99\%) and $\mathrm{Yb}_{2} \mathrm{O}_{3}($ Sigma Aldrich, 99.9\%). The starting mixtures were ground in ethanol using a planetary ball mill. The dried mixtures were heated at $750^{\circ} \mathrm{C}$ for $24 \mathrm{~h}$, then cooled and reground. The samples were then heated at $850^{\circ} \mathrm{C}$ for $24 \mathrm{~h}$, cooled, reground and reheated to $950^{\circ} \mathrm{C}$ for a further $24 \mathrm{~h}$. Samples were then slow cooled in air to room temperature over a period of approximately $5 \mathrm{~h}$. For electrical measurements, samples were subsequently pelletised, pressed isostatically at a pressure of $400 \mathrm{MPa}$ and sintered at $950^{\circ} \mathrm{C}$ for $10 \mathrm{~h}$, before slow cooling in air to room temperature over a period of $\mathrm{ca} .5 \mathrm{~h}$. 


\section{Diffraction}

X-ray powder diffraction data were obtained on a Philips X'Pert Pro diffractometer fitted with an $X^{\prime}$ Celerator detector, using Ni filtered $\mathrm{Cu} \mathrm{K \alpha}$ radiation $\left(\lambda_{1}=1.54056 \AA\right.$ and $\lambda_{2}=1.54439$ $\AA$ ). Data were collected in flat plate $\theta / \theta$ geometry and calibrated against an external Si standard. Room temperature data, suitable for detailed Rietveld refinement, were collected in the $2 \theta$ range 5$125^{\circ}$, in steps of $0.0167^{\circ}$, with an effective scan time of $250 \mathrm{~s}$ per step. Elevated temperature measurements were performed using an Anton-Paar HTK 1200 camera at selected temperatures from $100^{\circ} \mathrm{C}$ to $850^{\circ} \mathrm{C}$. Data were collected in the $2 \theta$ range $5-125^{\circ}$, in steps of $0.033^{\circ}$, with an effective scan time of $50 \mathrm{~s}$ per step for all but the data at $800^{\circ} \mathrm{C}$, where the room temperature scan parameters were used.

Neutron powder diffraction data were obtained on the Polaris diffractometer at the ISIS Facility, Rutherford Appleton Laboratory for the $x=0.2,0.4$ and 0.6 compositions. Data were collected on back-scattering $\left(130-160^{\circ}\right), 90^{\circ}\left(85-95^{\circ}\right)$, low-angle $\left(28-42^{\circ}\right)$ and very low angle (13$15^{\circ}$ ) detectors, over the respective time of flight ranges 1.0 to $20 \mathrm{~ms}, 0.8$ to $19.2 \mathrm{~ms}, 0.5$ to $20 \mathrm{~ms}$ and 2.0 to $18.6 \mathrm{~ms}$. Room temperature measurements were made with the sample contained in a cylindrical vanadium can (standard $11 \mathrm{~mm}$ diameter can for $x=0.2$ and 0.4 and a thin walled $8 \mathrm{~mm}$ diameter can for $x=0.6$ ) located in front of the back-scattering detectors. For the $x=0.2$ and 0.4 compositions, data collections of $c a .200 \mu \mathrm{A} \mathrm{h}$ were made, while for the $x=0.6$ composition, a longer data set of $1000 \mu \mathrm{A} \mathrm{h}$ was collected for total scattering analysis. Elevated temperature measurements were made from $300^{\circ} \mathrm{C}$ to $800^{\circ} \mathrm{C}$ in steps of $50^{\circ} \mathrm{C}$ in an evacuated furnace, with samples contained in an evacuated sealed silica tube inside an $8 \mathrm{~mm}$ diameter vanadium can for the $x=0.6$ composition, while for the $x=0.2$ and 0.4 compositions, samples were contained directly in an $11 \mathrm{~mm}$ diameter vanadium can. The use of a sealed silica tube in measurements on the $x=0.6$ sample was to minimise possible reduction of the sample while heating at elevated temperatures for extended times, as required for the total scattering measurements. Data collections of $c a .30 \mu \mathrm{A} \mathrm{h}$ were made at temperatures from $300^{\circ} \mathrm{C}$ to $750^{\circ} \mathrm{C}$, while at $800^{\circ} \mathrm{C}$ data collections of $200 \mu \mathrm{A}$ h were made for detailed Rietveld analysis. For the total scattering analysis data correction, diffraction data were collected on an empty vanadium can and an empty silica tube inside a vanadium can for $c a$. $700 \mu \mathrm{A}$ h under identical conditions to the sample.

Average structure refinement was carried out by Rietveld analysis with the GSAS suite of

programs,${ }^{38}$ using a combination of equally weighted X-ray and neutron data sets. A cubic model in 
space group Fm-3m was used for all refinements, $\mathrm{Bi}, \mathrm{Nb}$ and $\mathrm{Yb}$ were located on the ideal $4 a$ site $(0,0,0)$, with oxide ions distributed over three sites; $8 c$ at $(0.25,0.25,0.25), 32 f$ at approximately $(0.3,0.3,0.3)$ and $48 i$ at around $(0.5,0.2,0.2) .{ }^{36}$ For the $x=0.2$ composition at room temperature, the position of the $48 i$ site refined to that of the $24 d$ site $(0.5,0.25,0.25)$ and in the final refinements was fixed on this site. Crystal and refinement parameters for the data collected at room temperature and at $800^{\circ} \mathrm{C}$ are given in Tables 1 and 2 , respectively.

\section{Total Neutron Scattering Analysis}

Analysis of total neutron scattering data at room temperature for $\mathrm{Bi}_{3} \mathrm{Nb}_{0.4} \mathrm{Yb}_{0.6} \mathrm{O}_{6.4}$, was carried out using reverse Monte Carlo modelling. Data were corrected for background scattering and beam attenuation using the program Gudrun. ${ }^{39}$ The normalized total scattering structure factors, $S(Q)$, the total radial distribution function, $G(r)$, and the Bragg data (back scattering bank) were fitted using the RMCProfile software. ${ }^{40}$ A supercell configuration of $10 \times 10 \times 10$ crystallographic unit cells was used in calculations. The initial model was based on that of the ideal fluorite structure, with cations and anions randomly distributed over sites in the supercell, corresponding to the regular $4 a$ and $8 c$ crystallographic positions, respectively, in the cubic Fm-3m subcell. Parallel calculations were carried out on a set of ten random configurations in order to calculate standard deviations and improve statistics in the radial distributions. The $S(Q)$ function was broadened by convolution with a box function to reflect the finite size of the simulation box. Calculations were performed using bond valence summation (BVS) constraints $^{41}$ and an O-O closest approach constraint (to avoid unrealistically short $\mathrm{O}-\mathrm{O}$ contacts). Cation swapping (one random cation swapping positions with a random cation of another species) was tested and found to have no significant influence on the fit. The fitted $S(Q)$ and $G(r)$ data for $\mathrm{Bi}_{3} \mathrm{Nb}_{0.4} \mathrm{Yb}_{0.6} \mathrm{O}_{6.4}$ at room temperature are shown in Fig. 1. Further details on the background to total scattering analysis are discussed by Keen. ${ }^{42}$

\section{Electrical measurements}

Electrical parameters were determined by a.c. impedance spectroscopy up to $c a .840^{\circ} \mathrm{C}$, using a fully automated Solartron 1255/1286 system, in the frequency range $1 \mathrm{~Hz}$ to $5 \times 10^{5} \mathrm{~Hz}$. Samples for impedance measurements were prepared as rectangular blocks $\left(\mathrm{ca} .6 \times 3 \times 3 \mathrm{~mm}^{3}\right)$ cut from slow cooled sintered pellets using a diamond saw. Platinum electrodes were sputtered by cathodic discharge on the two smallest faces. Impedance spectra were acquired over two cycles of heating and cooling at stabilised temperatures. Impedance at each frequency was measured 
repeatedly until consistency ( $2 \%$ tolerance in drift) was achieved, or a maximum number of 25 repeats had been reached. ${ }^{43}$

Transference numbers were measured using a modified EMF method, with an external adjustable voltage source in the concentration cell $\mathrm{O}_{2}\left(\mathrm{pO}_{2}=1.01 \times 10^{5} \mathrm{~Pa}\right): \mathrm{Pt} \mid$ oxide $\mid \mathrm{Pt}: \mathrm{O}_{2}$ $\left(\mathrm{pO}_{2}=0.2095 \times 10^{5} \mathrm{~Pa}\right)$ as described in detail elsewhere. ${ }^{44}$ Cylindrical pellets of $\mathrm{ca} .15 \mathrm{~mm}$ diameter and $c a .1 .5 \mathrm{~mm}$ thickness were prepared under identical conditions to those used for impedance measurements. The pellets had their surfaces mirror-polished using successive SiC papers up to 4000 grit. Porous Pt electrodes of $10 \mathrm{~mm}$ diameter were sputtered using a Bal-Tec SCD 500 coater. The prepared pellets were sealed to the end of an alumina tube using Aremco 503 high temperature ceramic sealant. Measurements were performed on cooling, between $c a .800^{\circ} \mathrm{C}$ and $c a$. $500^{\circ} \mathrm{C}$ at stabilized temperatures. A flow of pure oxygen was maintained at $c a .2 .5 \mathrm{~cm}^{3} \mathrm{~s}^{-1}$ on one side of the sample, while the other side of the sample was exposed to ambient air. The oxygen partial pressure in and out of the cell was monitored using two Rapidox 2100 electrochemical oxygen sensors and cell voltage was measured using a Keithley 2182A nanovoltmeter. An external voltage source was connected to the cell and current measured using a Keithley 2400 source meter. A Solartron 1260 impedance analyser was used for a.c. measurements. Impedance spectra were measured in the frequency range $0.3 \mathrm{~Hz}$ to $1 \mathrm{MHz}$ and the a.c. signal was $30 \mathrm{mV}$ rms. Fitting of equivalent circuit parameters to the impedance spectra was performed using the FIRDAC program. ${ }^{45}$ At each temperature the following sequence was performed: stabilization for 6 hours; measurement of the open circuit voltage; a series of d.c. measurements using an external voltage ranging from the open circuit voltage to the appropriate Nernst voltage; impedance measurements.

\section{Differential Thermal Analysis}

Differential thermal analysis (DTA) was carried out using a TA Instruments Q600 scanning differential thermal analyser. Approximately $60 \mathrm{mg}$ of powdered sample in an alumina crucible was monitored over heating and cooling cycles, between ambient temperature and $1000^{\circ} \mathrm{C}$ at a heating rate of $20^{\circ} \mathrm{C} \min ^{-1}$ in flowing air.

\section{Results and Discussion}

The diffraction profiles for the $x=0.2,0.4$ and 0.6 (Supplementary Figs S1 to S3) were fitted to the cubic fluorite structure in space group $F m-3 m$. In the case of the $x=0.8$ composition, a mixture was observed, with diffraction patterns showing peaks arising from the cubic fluorite phase, 
as well as those from an orthorhombic phase, believed to be $\mathrm{Bi}_{17} \mathrm{Yb}_{7} \mathrm{O}_{36}{ }^{27}$ Despite several attempts, using different synthesis conditions, it was not possible to isolate the $x=0.8$ composition as a pure phase and further discussion is limited to the single phase compositions. Thermal analysis on the single phase compounds showed no significant thermal events up to $c a \cdot 1000^{\circ} \mathrm{C}$. The DTA thermogram for the $x=0.6$ composition is typical and is shown in Fig. 2.

Fig. 3 shows detail of the backscattered neutron diffraction patterns and reveals that at low levels of substitution, additional peaks are evident due to superlattice ordering. As the level of substitution increases, these superlattice peaks are replaced by a broad background feature, characteristic of short range order. The superlattice peaks observed in the neutron diffraction pattern of the $x=0.2$ composition correspond to the incommensurately modulated type II phase, known to occur at the $x=0.0$ composition. ${ }^{21-23}$ This phase shows a complex 3 dimensional incommensurate modulation, such that any Bragg peak can be indexed using six indices, $h, k, l, m, n, p:^{15}$

$$
\frac{1}{d_{h k l m n p}^{2}}=\frac{h^{2}+k^{2}+l^{2}+\varepsilon\left(m^{2}+n^{2}+p^{2}\right)}{a^{2}}
$$

where $\varepsilon$ is the modulation parameter and describes the relationship between the commensurate and incommensurate substructures. Eqn 1 is more readily applicable in reciprocal space and can be rewritten as follows:

$$
\frac{d^{*^{2}}}{a^{*^{2}}}=\left(h^{2}+k^{2}+l^{2}\right)+\varepsilon\left(m^{2}+n^{2}+p^{2}\right)
$$

Thus a plot of $\frac{d^{*^{2}}}{a^{*^{2}}}-\left(h^{2}+k^{2}+l^{2}\right)$ against $\left(m^{2}+n^{2}+p^{2}\right)$ can be fitted to a straight line passing through the origin, the slope of which equals $\varepsilon$. In this case, by fitting to eqn 2 the value of $\varepsilon$ was found to be $0.386(3)$, which is comparable to the values obtained for the $x=0.0$ composition of 0.37 15 and $0.383 .^{20}$ 
The refined structural parameters for the studied compositions, obtained through Rietveld refinement, using X-ray and neutron diffraction data collected at room temperature and at $800^{\circ} \mathrm{C}$, are given in Table 3. Over the solid solution range studied, oxide ions were found to occupy four crystallographically distinct sites. The relative locations of these sites with respect to the fluorite unit cell are illustrated in Fig. 4. For the $x=0.2$ composition, which exhibited the type II incommensurate structure at room temperature, the $24 d$ site gave a better description of the interstitial oxide ion scattering, as has been observed in other type II systems, such as $\mathrm{Bi}_{3} \mathrm{Ta}_{1 \text { - }}$ ${ }_{x} \mathrm{Nb}_{x} \mathrm{O}_{7}{ }^{46}$ The oxide ion site occupancies showed both compositional and thermal dependences as shown in Fig. 5. The occupancy of the $8 c$ site is seen to increase at the expense of the $32 f$ site, with increasing $\mathrm{Yb}$ content. This trend is similar to that seen in the $\mathrm{Nb} / \mathrm{Y}$ analogue ${ }^{36}$ and can be associated with the change in the degree of distortion of the average dopant polyhedron, with more distortion of the niobate polyhedra (distorted niobate trigonal anti-prisms in the $x=0.0$ composition ${ }^{23}$ ), compared to the less distorted ytterbate polyhedra (a distorted octahedral coordination for $x=$ $\left.1.0^{34}\right)$. The oxide ion content in the $48 i / 24 d$ sites does not vary significantly with composition in this system. This can be explained by considering that occupancy of these sites is only found in substituted bismuth oxides and is associated with coordination to the substituent cations. ${ }^{36,37}$ In the present study, the overall level of bismuth substitution remains the same throughout the studied compositions and since the ytterbate and niobate polyhedra both involve coordination to ions in the $48 i / 24 d$ sites, the number of ions in these sites is not expected to show significant compositional variation. There are significant changes in oxide ion distribution with temperature. The number of ions in the $48 \mathrm{i} / 24 d$ sites is seen to increase, while the site occupancy of the $32 f$ site decreases and that of the $8 c$ site increases at elevated temperature. The observed trends are somewhat different to those seen in the $\mathrm{Bi}_{3} \mathrm{Nb}_{1-x} \mathrm{Y}_{x} \mathrm{O}_{7-x}$ system, where the $32 f$ site was seen to increase in occupancy at the expense of $8 c$ at $800^{\circ} \mathrm{C}$. Oxide ions in the $32 f$ site are related to those in the $8 c$ site by a small shift in the $<111>$ direction. Ions on both these crystallographic sites can be considered to lie within the tetrahedral cavity of the $c c p$ fluorite lattice. Changes in the $32 f / 8 c$ site occupancy ratio reflect the degree of positional disorder on the anion sublattice and are strongly correlated with changes in the isotropic thermal parameter and the $32 f$ site positional parameters.

The thermal variation of the cubic lattice parameter for the studied compositions is shown in Fig. 6. All the plots show two linear regions, one at low temperatures and another at high temperatures, which are separated by an intermediate temperature region, the extent of which decreases with increasing $\mathrm{Yb}$ content. The low temperature region extends to around $400^{\circ} \mathrm{C}$, while the onset of the high temperature region varies from around $500^{\circ} \mathrm{C}$, at $x=0.6$, to around $600^{\circ} \mathrm{C}$ at $x$ $=0.2$. For all compositions, in the high temperature region, a general increase in lattice parameter 
is observed with increasing level of $\mathrm{Yb}$ content. In order to explain the compositional variation of lattice parameter at elevated temperature, the solid solution mechanism needs to be considered and may be summarised as:

$$
\mathrm{Nb}_{\mathrm{Nb}}^{\mathrm{X}}+\mathrm{O}_{\mathrm{O}}^{\mathrm{X}} \rightarrow \mathrm{Yb}_{\mathrm{Nb}}{ }^{\prime \prime}+V_{\mathrm{O}}^{\bullet \bullet}
$$

Substitution of $\mathrm{Nb}^{5+}$ by the larger $\mathrm{Yb}^{3+}$ ion (with ionic radii of $0.64 \AA$ and $0.868 \AA$, respectively for coordination number $=6^{47}$ ) would be expected to result in a linear increase in lattice parameter. The observed non-linear behaviour in the thermal variation of lattice parameter is associated predominantly with changes in oxide ion distribution. In particular, while changes in the $32 f / 8 c$ occupancy ratio are expected to have little influence on the size of the lattice, since ions on both these crystallographic positions reside within the tetrahedral cavity of the $c c p$ fluorite lattice, an increase in ion concentration on the $48 i$ or $24 d$ sites would be expected to result in an increase in the lattice dimension, since these sites are interstitial to the fluorite lattice. This type of behaviour is seen in many of the substituted bismuth oxides, e.g. ${ }^{36,37}$

Fig. 7 shows the M-O pair correlations, $\mathrm{g}_{\mathrm{M}-\mathrm{O}}(r)$, calculated by RMC analysis of neutron total scattering data from the $x=0.6$ composition, at room temperature. For each pair, the first maximum in the plots corresponds to the modal contact distance, with integration to the first deep minimum giving the site coordination number. An alternative approach is to use the sum of the ionic radii as a maximum distance and integrate to this maximum to yield the local coordination number. An average contact distance can then be calculated as the mean over contacts below the maximum distance. This latter approach is best suited to cations such as bismuth, which typically show an asymmetric coordination geometry, due to stereochemical activity of the $6 s^{2}$ lone pair of electrons. The distances and coordination numbers derived using the two approaches are summarised in Table 4.

The modal contact distances for $\mathrm{Bi}-\mathrm{O}$ and $\mathrm{Yb}-\mathrm{O}$ are close to the sum of the ionic radii. The modal contact distance for $\mathrm{Nb}-\mathrm{O}$ is significantly longer than the sum of the ionic radii, but both values lie well within the range seen in the parent oxide $\left(1.77 \AA\right.$ to $2.47 \AA$ for $\mathrm{Nb}-\mathrm{O}$ in $\mathrm{h}-\mathrm{Nb}_{2} \mathrm{O}_{5}{ }^{48}$ ). Both $\mathrm{Yb}-\mathrm{O}$ distances in Table 4 are slightly lower than that seen in the parent oxide $(2.22 \AA$ to 2.29 $\AA$ for $\mathrm{Yb}-\mathrm{O}$ in $\mathrm{Yb}_{2} \mathrm{O}_{3}{ }^{49}$ ). Coordination numbers calculated using the ionic radii approach are consistently lower than those found using the minimum in $g(r)$ approach. In the case of $\mathrm{Bi}$, the ionic radii approach gives a better estimate of coordination number, reflecting the stereochemical activity 
of the $6 s^{2}$ electron pair and is consistent with predominantly four-fold pyramidal geometry for this atom, as is commonly observed in bismuth oxides. The minimum in $g(r)$ approach is better suited to $\mathrm{Nb}$ and $\mathrm{Yb}$ atoms, with estimated coordination numbers for both these atoms around 5.

Using the coordination numbers derived from the RMC calculations and the atomic coordinates from the Rietveld analysis, it is possible to propose model coordination polyhedra for the different cations present in the $x=0.6$ composition. Fig. 8 summarises these polyhedra. It is assumed that the interstitial oxide ions on the $48 i$ site are exclusively associated with $\mathrm{Nb}$ and/or $\mathrm{Yb}$, as occupancy of this site is not observed in pure $\delta-\mathrm{Bi}_{2} \mathrm{O}_{3}$. Thus the coordination of bismuth is assumed to be entirely made up of oxide ions in the tetrahedral cavities ( $32 f$ and $8 c$ sites). A four pyramidal geometry (Fig. 8a) is readily obtained assuming a coordination number of four, as suggested by the RMC analysis. The niobium coordination number is around five according to the $\mathrm{RMC}$ analysis and it is evident from the Rietveld analysis that Nb-rich compositions show little or no occupation of the $8 c$ sites. Therefore, the coordination polyhedra for $\mathrm{Nb}$ can be considered as being made up entirely of oxide ions located on the $32 f$ and $48 i$ sites. Both four and six coordinate polyhedra are common in niobium oxides and examples of each are shown in Fig, 8b and Fig. 8c. It is interesting to note that in the recently determined structure of type II bismuth niobate (corresponding to compositions close to $x=0$ in the present system), niobium coordination was found to be predominantly six coordinate. ${ }^{23}$ The $8 c$ site appears to be more favoured in Yb-rich compositions and a simple five coordinate geometry is readily obtained as a distorted truncated octahedron (Fig. 8d). Whilst the coordination polyhedra shown in Fig.8 are based on the RMC and Rietveld analyses, the possibility of a combination of other coordination polyhedra cannot be excluded, as these models are derived from the average structure.

The final RMC configuration can readily be examined for the presence and ordering of oxide ion vacancies as previously described. ${ }^{33,34}$ As stated above, oxide ions in the $32 f$ and $8 c$ sites can be considered to reside within the tetrahedral cavities of the fluorite lattice, while those in the $48 i / 24 d$ sites can be thought of as Frenkel interstitials, ${ }^{50}$ which result in an increased vacancy concentration in the tetrahedral cavities. The observed vacancy concentration per cell for $\mathrm{Bi}_{3} \mathrm{Nb}_{0.4} \mathrm{Yb}_{0.6} \mathrm{O}_{6.4}$ from the final $\mathrm{RMC}$ configuration is given in Table 5 and is compared with values obtained from the Rietveld analysis for the same composition, as well as values obtained for the other compositions studied. Table 5 also shows theoretical values calculated using two models. Model 1 assumes that all oxide ions are located in the tetrahedral cavities, while model 2 assumes that oxide ions are also located in interstitial sites at a ratio of one interstitial ion per dopant cation. The results clearly show that model 2 provides a closer description of the oxide ion distribution in this system. As expected, the observed and calculated vacancy concentrations increase with 
increasing value of $x$. At $800^{\circ} \mathrm{C}$, higher vacancy concentrations are observed than at room temperature, for all compositions. This is reflected in increased occupancy of the interstitial sites at high temperatures (Table 3 ). It should be noted that the data quality for the $x=0.6$ composition, at room temperature, was significantly higher than that for the other compositions and this is reflected in the lower estimated standard deviations for occupancy parameters for this composition in Table 3. A higher vacancy concentration is seen for the $x=0.6$ composition at room temperature in the RMC configuration compared to that from the Rietveld analysis. This difference is associated with the fact that in the Rietveld analysis, an average isotropic thermal parameter is used to describe the positional disorder of all oxide ions, whereas in analysis of the RMC configuration a cut off is used to determine whether an ion in the configuration lies within the tetrahedral cavity or not. In this case, where oxide ions were at a distance greater than $1 \AA$ away from the centre of the tetrahedral cavity, they were considered to be interstitial. This value is based the $48 i \ldots 8 c$ and $32 f \ldots 8 c$ distances obtained from the Rietveld analysis.

The RMC configuration was further examined to reveal details of vacancy ordering in the model. Three basic vacancy pair alignments are possible: $\langle 100\rangle,\langle 110\rangle$ and $\langle 111\rangle$, with distances between vacancies of $a / 2, \sqrt{ } 2 a / 2$ and $\sqrt{ } 3 a / 2$, respectively. ${ }^{33,34}$ The configuration for $\mathrm{Bi}_{3} \mathrm{Nb}_{0.4} \mathrm{Yb}_{0.6} \mathrm{O}_{6.4}$ reveals a respective ratio of 1:1.76:1.06, which compares to a ratio of 1:2:1.33 for a purely random distribution of vacancy pairs. This indicates a favouring of $\langle 100\rangle$ pairs in excess of that in the random distribution and is consistent with density functional theory (DFT) and molecular dynamics (MD) studies on $\delta-\mathrm{Bi}_{2} \mathrm{O}_{3}$, which show $\langle 100\rangle$ as energetically the most stable configuration. $^{51,52}$ The predominance of $\langle 110\rangle$ pairs is explained by the statistical probability of this pair ordering, since there are twice as many locations for <110> pairs per cell than for other vacancy pair alignments. It is important to consider that the additional Frenkel vacancies in the studied system, mean a high likelihood of multiple vacancy clustering ${ }^{53}$ and that a simple analysis of vacancy pair distributions is not necessarily reflective of the situation at such high vacancy concentrations.

The Arrhenius plots of total conductivity for the studied single phase compositions are shown in Fig. 9. For compositions $x=0.2$ to 0.6 , plots were fully reproducible over two cycles of heating and cooling. In general, two linear regions are observed; a low temperature region extending to around $450^{\circ} \mathrm{C}$ and a high temperature region above $c a .600^{\circ} \mathrm{C}$. Between these temperature regions, a transitional region is observed, which shows a gradual change in activation energy. For the $x=0.2$ composition, a higher activation energy is observed in the high temperature region than that in the low temperature region, while the situation is reversed for compositions $x=$ 0.4 and 0.6. This behaviour is similar to that seen in the $\mathrm{Bi}_{3} \mathrm{Nb}_{1-x} \mathrm{Y}_{x} \mathrm{O}_{7-x}$ system, ${ }^{36}$ where it has been 
associated with the contribution of electronic conduction to the total conductivity at low temperatures in Nb-rich compositions. ${ }^{54}$ The derived electrical parameters for the studied compositions are summarised in Table 6. The conductivity in the low temperature region, characterised by that at $300^{\circ} \mathrm{C}\left(\sigma_{300}\right)$, and that in the high temperature region, characterised by that at $800^{\circ} \mathrm{C}\left(\sigma_{800}\right)$, both show increasing trends with increasing $\mathrm{Yb}$ content, i.e. increasing vacancy concentration. The low temperature activation energy, $\Delta E_{\mathrm{LT}}$, shows little compositional variation, while that corresponding to the high temperature region, $\Delta E_{\mathrm{HT}}$, shows a decrease with increasing level of substitution. These trends reflect those observed in the compositional variation of lattice parameter in the low temperature and high temperature regions, with a significant compositional change in lattice dimension only at high temperatures. The variation of $\Delta E_{\mathrm{HT}}$ is also consistent with decreased defect trapping effects caused by the substitution of pentavalent niobium by trivalent ytterbium. This type of behaviour is also seen in the $\mathrm{Bi}_{2} \mathrm{O}_{3}-\mathrm{Y}_{2} \mathrm{O}_{3}-\mathrm{Nb}_{2} \mathrm{O}_{5}{ }^{36}$ and $\mathrm{Bi}_{2} \mathrm{O}_{3}-\mathrm{Er}_{2} \mathrm{O}_{3}-\mathrm{Nb}_{2} \mathrm{O}_{5}$ systems. $^{37}$

Fig. 10 shows the thermal variation of oxide ion transference number for the studied compositions. All compositions show predominantly ionic conductivity over the temperature range studied. The lowest ionic transference numbers are seen for the $x=0.2$ composition, which shows electronic contributions of up to $c a$. $20 \%$. Ionic transference number is seen to increase with increasing $\mathrm{Yb}$ content. This is similar to the situation seen in the yttrium analogue, ${ }^{54}$ which was explained by considering the structure of the type II phase exhibited by niobium rich compositions ${ }^{23}$ and is characterised by chains of niobate polyhedra, along which polaron hopping is a possible conduction mechanism. Substitution of niobium by ytterbium disrupts these chains, which would result in a lowering of electronic conductivity, such that at the $x=0.6$ composition, conductivity is almost exclusively ionic, with ionic transference numbers close to unity at elevated temperatures.

\section{Conclusions}

An extensive solid solution is seen in the $\mathrm{Bi}_{3} \mathrm{Nb}_{1-x} \mathrm{Yb}_{x} \mathrm{O}_{7-x}$ system, with both ordered and disordered fluorites observed. At compositions above $x=0.2$, a fully disordered $\delta-\mathrm{Bi}_{2} \mathrm{O}_{3}$ type phase is seen. However, it is difficult to prepare a pure phase at $x=0.8$. The oxide ion distribution is found to show compositional and thermal dependencies. Occupation of two closely related sites is found within the tetrahedral cavities of the fluorite lattice, the $8 c$ site which corresponds to the centre of the tetrahedral cavity and the $32 f$ site, which is shifted in the $\langle 111\rangle$ direction. Nb-rich compositions appear to favour the $32 f$ site. Coordination numbers, derived from total neutron scattering analysis, indicate the coordination number of bismuth is close to four, which is consistent with 
stereochemical activity of the non-bonding $6 s^{2}$ electrons. A niobium coordination number of five was found and can be obtained by a distribution of four coordinate and six coordinate polyhedra. $\mathrm{Yb}$ also shows a coordination number close to five and an alternative truncated octahedral coordination geometry for this atom is suggested as a possibility.

Vacancy pairs in $\mathrm{Bi}_{3} \mathrm{Nb}_{0.4} \mathrm{Yb}_{0.6} \mathrm{O}_{6.4}$ show a non-random preference for $<100>$ ordering, despite a statistical predominance of $\langle 110\rangle$ pairs. However, the total number of vacancies in the system is significantly greater than the nominal vacancy concentration of (1.6 vacancies per fluorite cell) being closer to 3 vacancies per cell, with additional vacancies occurring via Frenkel defects.

Ionic conductivity is high in the studied system, with values as high as $0.4 \mathrm{~S} \mathrm{~cm}^{-1}$ at $800^{\circ} \mathrm{C}$. Transference number measurements show that conductivity in this system is predominantly ionic at temperatures above $\mathrm{ca} .450^{\circ} \mathrm{C}$.

\section{Acknowledgements}

We gratefully acknowledge the Science and Technology Facilities Council (STFC) ISIS facility at the Rutherford Appleton Laboratory for neutron beam time. We wish to thank The National Centre for Research and Development (Poland) for grant no. DKO/Pl-TW1/6.

\section{Notes and references}

${ }^{a}$ Faculty of Physics, Warsaw University of Technology, ul. Koszykowa 75, 00-662 Warszawa, Poland.

${ }^{b}$ Centre for Materials Research, School of Biological and Chemical Sciences, Queen Mary University of London, Mile End Road, London E1 4NS, U.K.

${ }^{c}$ Chalmers University of Technology, Department of Chemical and Biological Engineering, SE41296 Gothenburg, Sweden.

${ }^{d}$ ISIS Facility, Rutherford Appleton Laboratory, Chilton, Didcot, Oxon OX11 0QX, UK.

1. A. Watanabe, M. Sekita, Solid State Ionics, 176 (2005) 2429.

2. K.Z. Fung H.D. Baek, A. Virkar, Solid State Ionics, 52 (1992) 199.

3. K. Huang, M. Feng, J. B. Goodenough, Solid State Ionics, 89 (1996) 17.

4. N. Jiang, E.D. Wachsman, S.-H. Jung, Solid State Ionics, 150 (2002) 347.

5. E.D. Wachsman and K.T. Lee, Science, 334 (2011) 935. 
6. E.D. Wachsman, C. A. Marlowe, K.T. Lee, Energy Env. Sci., 5 (2012) 5498.

7. T. Takahashi, H. Iwahara, Y. Nagaj, J. Appl. Electrochem., 2 (1972) 97.

8. G. Mairesse, in Fast Ion Transport in Solids, B. Scrosati, A. Magistris, C.M. Mari, G. Mariotto (Eds.), Kluwer Academic Publishers, Dordrecht, 1993, p271.

9. J.C. Boivin, G. Mairesse, Chem. Mater., 10 (1998) 2870.

10. P. Shuk, H.D. Wiemhöfer, U. Guth, W. Göpel, M. Greenblatt, Solid State Ionics, 89 (1996) 179.

11. N.M. Sammes, G.A. Tompsett, H. Näfe, F. Aldinger, J. Eur. Ceram. Soc., 19 (1999) 1801.

12. A.M. Azad, S. Larose, S.A. Akbar, J. Mater. Sci., 29 (1994) 4135.

13. M. Drache, P. Rooussel, J-P. Wignacourt, Chem. Rev., 107 (2007) 80

14. W. Zhou, D.A. Jefferson, J.M. Thomas, Proc. R. Soc. Lond. A, 406 (1986) 173.

15. C.D. Ling, R.L. Withers, S. Schmid, J.G. Thompson, J. Solid State Chem., 137 (1998) 42.

16. A. Castro, E. Aguado, J.M. Rojo, P. Herrero, R. Enjalbert, J. Galy, Mater. Res. Bull., 33 (1998) 31.

17. C.D. Ling, M. Johnson, J. Solid State Chem., 177 (2004) 1838.

18. R.L. Withers, C.D. Ling, S. Schmid, Z. Kristallogr. 214 (1999) 296.

19. M. Valant, D. Suvorov, J. Am. Ceram. Soc., 86 (2003) 939.

20. X.P. Wang, G. Corbel, S. Kodjikian, Q.F. Fang, P. Lacorre, J. Solid State Chem., 179 (2006) 3338.

21. W. Zhou, J. Solid State Chem., 101 (1992) 1.

22. C.D. Ling, J. Solid State Chem., 148 (1999) 380.

23. C.D. Ling, S. Schmid, P.E.R. Blanchard, V. Petrícek, G.J. McIntyre, N. Sharma, A. Maljuk, A.A. Yaremchenko, V.V. Kharton, M. Gutmann, R.L. Withers, J. Amer. Chem. Soc., 135 (2013) 6477.

24. R.K. Datta, J.P. Meehan, Z. Anorg. Allgem. Chem., 383 (1971) 328.

25. H. Iwahara, T. Esaka, T. Sato, T. Takahashi, J. Solid State Chem, 39 (1981) 173.

26. X.L. Chen, F.F. Zhang, Y.M. Shen, J.K. Liang, W.H. Tang, Q.Y. Tu, J Solid State Chem., 139 (1998) 398.

27. M. Drache, P. Roussel, J.P. Wignacourt, P. Conflant, Mater. Res. Bull., 39 (2004) 1393.

28. S. Boyapati, E.D. Wachsman, B.C. Chakoumakos, Solid State Ionics, 138 (2001) 293.

29. S. Boyapati, E.D. Wachsman, N. Jiang, Solid State Ionics, 140 (2001) 140.

30. E.D. Wachsman, J. Eur. Ceram. Soc., 24 (2004) 1281.

31. P.D. Battle, C.R.A. Catlow, L.M. Moroney, J. Solid State Chem., 67 (1987) 42.

32. M. Yashima, D. Ishimura, Appl. Phys. Lett., 87 (2005) 221909.

33. M. Leszczynska, X. Liu, W. Wrobel, M. Malys, M. Krynski, S.T. Norberg, S. Hull, F. Krok, I. Abrahams, Chem. Mater., 25 (2013) 326. 
34. M. Leszczynska, X. Liu, W. Wrobel, M. Malys, S.T. Norberg, S. Hull, F. Krok and I.

Abrahams, J. Phys.: Condens. Matter., 25 (2013) 454207.

35. G. Meng, C. Chen, X. Han, P. Yang, D. Peng, Solid State Ionics, 28-30 (1988) 533.

36. I. Abrahams, A. Kozanecka-Szmigiel, F. Krok, W. Wrobel, S.C.M. Chan, and J.R. Dygas, Solid State Ionics, 177 (2006) 1761.

37. M. Leszczynska, M. Holdynski, F. Krok, I. Abrahams, X. Liu and W. Wrobel, Solid State Ionics, 181 (2010) 796.

38. A. C. Larson, R. B. Von Dreele, Los Alamos National Laboratory Report, No. LAUR-86-748, (1987).

39. A. K. Soper, unpublished software.

40. M. G. Tucker, D. A. Keen, M. T. Dove, A. L. Goodwin, Q. Hui, J. Phys.: Condens. Matter, 19 (2007) 335218.

41. S. T. Norberg, M. G. Tucker, S. Hull, J. Appl. Cryst., 42 (2009) 179.

42. D. A. Keen. J. Appl. Cryst., 34 (2001) 172.

43. J.R. Dygas, P. Kurek, M.W. Breiter, Electrochim. Acta, 40 (1995) 1545.

44. M. Malys, J.R. Dygas, M. Holdynski, A. Borowska-Centkowska, W. Wrobel, M. Marzantowicz, Solid State Ionics, 225 (2012) 493.

45. J.R. Dygas, M.W. Breiter, Electrochim. Acta, 44 (1999) 4163.

46. M. Struzik, X. Liu, I. Abrahams, F. Krok, M. Malys, J.R. Dygas, Solid State Ionics, 218 (2012) 25.

47. R.D. Shannon, Acta Crystallogr., A32 (1976) 751-767.

48. K. Kato, Acta Crystallogr., B32 (1976) 764.

49. A. Fert, Bull. Soc. Fr. Mineral. Cristallogr. 85 (1962) 267-270.

50. I. Abrahams, X. Liu, S. Hull, S.T. Norberg, F. Krok, A. Kozanecka-Szmigiel, M. S. Islam, S.J. Stokes, Chem. Mater., 22 (2010) 4435-3345.

51. Walsh, A.; Watson, G. W.; Payne, D. J.; Edgell, R. G.; Guo, J.; Glans, P.-A.; Learmont, T.; Smith, K. E.; Phys. Rev. B. 73 (2006) 235104.

52. Aidhy, D. S.; Nino, J. C.; Sinnott, S. B.; Wachsman, E. D.; Phillpot, S. R.; J. Am. Ceram. Soc. $91(2008) 2349$.

53. Boyapati, S.; Wachsman, E. D.; Jiang, N.; Solid State Ionics 140 (2001) 149.

54. M. Małys, M. Hołdynski, F. Krok, W. Wróbel, J.R.Dygas, C.Pirovano, R-N. Vannier, E. Capoen, I.Abrahams J. Power Sources, 194 (2009) 16. 
Table 1

Crystal and Refinement Parameters for $\mathrm{Bi}_{3} \mathrm{Nb}_{1-x} \mathrm{Yb}_{x} \mathrm{O}_{7-x}$ at room temperature.

\begin{tabular}{|c|c|}
\hline Composition & $x=0.2$ \\
\hline Chemical formula & $\mathrm{Bi}_{3} \mathrm{Nb}_{0.8} \mathrm{Yb}_{0.2} \mathrm{O}_{6.8}$ \\
\hline Formula weight & 844.664 \\
\hline Crystal system & Cubic \\
\hline Space group & $F m-3 m$ \\
\hline Unit cell dimension & $a=5.46790(3) \AA$ \\
\hline Volume & $163.479(3) \AA^{3}$ \\
\hline $\mathrm{Z}$ & 1 \\
\hline $\begin{array}{l}\text { Density } \\
\text { (calculated) }\end{array}$ & $8.580 \mathrm{Mg} \mathrm{m}^{-3}$ \\
\hline$\mu(\mathrm{CuK} \alpha \mathrm{X}$-ray $)$ & $172.20 \mathrm{~mm}^{-1}$ \\
\hline $\mathrm{F}(000)$ & 350.2 \\
\hline Sample description & Yellow powder \\
\hline \multirow[t]{12}{*}{ R-factors ${ }^{a}$} & Neutron (back-scattering) \\
\hline & $\mathrm{R}_{\mathrm{wp}}=0.0341, \mathrm{R}_{\mathrm{p}}=0.0632$ \\
\hline & $\mathrm{R}_{\mathrm{ex}}=0.0065, \mathrm{R}_{\mathrm{F}} 2=0.1077$ \\
\hline & Neutron (low angle) \\
\hline & $\mathrm{R}_{\mathrm{wp}}=0.0694, \mathrm{R}_{\mathrm{p}}=0.0521$ \\
\hline & $\mathrm{R}_{\mathrm{ex}}=0.0229, \mathrm{R}_{\mathrm{F}} 2=0.0929$ \\
\hline & X-ray \\
\hline & $\mathrm{R}_{\mathrm{wp}}=0.0492, \mathrm{R}_{\mathrm{p}}=0.0327$ \\
\hline & $\mathrm{R}_{\mathrm{ex}}=0.0171, \mathrm{R}_{\mathrm{F}} 2=0.0300$ \\
\hline & Totals \\
\hline & $\mathrm{R}_{\mathrm{wp}}=0.0407, \mathrm{R}_{\mathrm{p}}=0.0330$ \\
\hline & $\chi^{2}=13.71$ \\
\hline No. of variables & 122 \\
\hline \multirow[t]{3}{*}{$\begin{array}{l}\text { No of profile points } \\
\text { used }\end{array}$} & $\begin{array}{l}3821 \text { (Neutron,back- } \\
\text { scattering) }\end{array}$ \\
\hline & 4641 (Neuton,low-angle) \\
\hline & 6281 (X-ray) \\
\hline \multirow[t]{3}{*}{ No of reflections } & 90 (Neutron,back-scattering) \\
\hline & 55 (Neuton,low-angle) \\
\hline & 31 (X-ray) \\
\hline
\end{tabular}

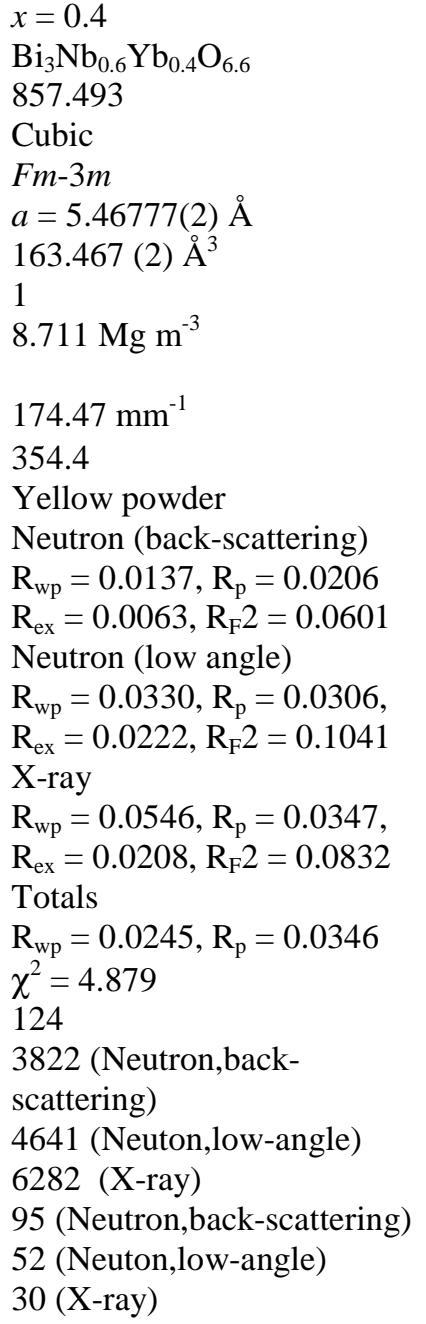

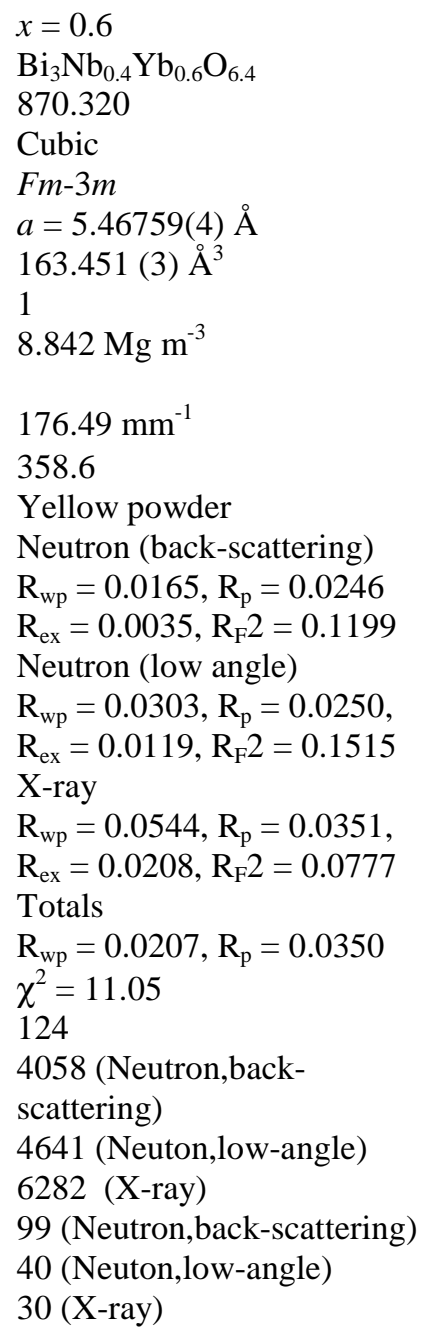

${ }^{a}$ For definition of R-factors see reference 38 
Table 2

Crystal and Refinement Parameters for $\mathrm{Bi}_{3} \mathrm{Nb}_{1-x} \mathrm{Yb}_{x} \mathrm{O}_{7-x}$ at $800^{\circ} \mathrm{C}$

\begin{tabular}{|c|c|}
\hline Composition & $x=0.2$ \\
\hline Chemical formula & $\mathrm{Bi}_{3} \mathrm{Nb}_{0.8} \mathrm{Yb}_{0.2} \mathrm{O}_{6.8}$ \\
\hline Formula weight & 844.664 \\
\hline Crystal system & Cubic \\
\hline Space group & $F m-3 m$ \\
\hline Unit cell dimension & $a=5.52622(4) \AA$ \\
\hline Volume & $168.766(3) \AA^{3}$ \\
\hline $\mathrm{Z}$ & 1 \\
\hline $\begin{array}{l}\text { Density } \\
\text { (calculated) }\end{array}$ & $8.311 \mathrm{Mg} \mathrm{m}^{-3}$ \\
\hline$\mu(\mathrm{CuK} \alpha \mathrm{X}$-ray $)$ & $166.83 \mathrm{~mm}^{-1}$ \\
\hline $\mathrm{F}(000)$ & 350.2 \\
\hline Sample description & Yellow powder \\
\hline \multirow[t]{11}{*}{ R-factors ${ }^{a}$} & Neutron (back-scattering) \\
\hline & $\mathrm{R}_{\mathrm{wp}}=0.0148, \mathrm{R}_{\mathrm{p}}=0.0275$ \\
\hline & $\mathrm{R}_{\mathrm{ex}}=0.0072, \mathrm{R}_{\mathrm{F}} 2=0.1483$ \\
\hline & Neutron (low angle) \\
\hline & $\mathrm{R}_{\mathrm{wp}}=0.0383, \mathrm{R}_{\mathrm{p}}=0.0340$ \\
\hline & $\mathrm{R}_{\mathrm{ex}}=0.0272, \mathrm{R}_{\mathrm{F}} 2=0.1304$ \\
\hline & X-ray \\
\hline & $\mathrm{R}_{\mathrm{wp}}=0.0475, \mathrm{R}_{\mathrm{p}}=0.0305$ \\
\hline & $\mathrm{R}_{\mathrm{ex}}=0.0210, \mathrm{R}_{\mathrm{F}} 2=0.0659$ \\
\hline & Totals \\
\hline & $\mathrm{R}_{\mathrm{wp}}=0.0246, \mathrm{R}_{\mathrm{p}}=0.0305$ \\
\hline No. of variables & $\begin{array}{l}\chi^{2}=3.927 \\
121\end{array}$ \\
\hline \multirow{4}{*}{$\begin{array}{l}\text { No of profile points } \\
\text { used }\end{array}$} & 3822 (Neutron,back- \\
\hline & scattering) \\
\hline & 4641 (Neuton,low-angle) \\
\hline & 6282 (X-ray) \\
\hline \multirow[t]{3}{*}{ No of reflections } & 96 (Neutron,back-scattering) \\
\hline & 56 (Neuton,low-angle) \\
\hline & 32 (X-ray) \\
\hline
\end{tabular}

${ }^{a}$ For definition of R-factors see reference 38

\begin{tabular}{|c|c|}
\hline$x=0.4$ & $x=0.6$ \\
\hline $\mathrm{Bi}_{3} \mathrm{Nb}_{0.6} \mathrm{Yb}_{0.4} \mathrm{O}_{6.6}$ & $\mathrm{Bi}_{3} \mathrm{Nb}_{0.4} \mathrm{Yb}_{0.6} \mathrm{O}_{6.4}$ \\
\hline 857.493 & 870.32 \\
\hline Cubic & Cubic \\
\hline$F m-3 m$ & $F m-3 m$ \\
\hline$a=5.53235(3) \AA$ & $a=5.53615(3) \AA$ \\
\hline $169.328(3) \AA^{3}$ & $169.677(2) \AA^{3}$ \\
\hline 1 & 1 \\
\hline $8.409 \mathrm{Mg} \mathrm{m}^{-3}$ & $8.517 \mathrm{Mg} \mathrm{m}^{-3}$ \\
\hline $168.43 \mathrm{~mm}^{-1}$ & $169.96 \mathrm{~mm}^{-1}$ \\
\hline 354.4 & 358.6 \\
\hline Yellow powder & Yellow powder \\
\hline Neutron (back-scattering) & Neutron (back-scattering) \\
\hline $\mathrm{R}_{\mathrm{wp}}=0.0076, \mathrm{R}_{\mathrm{p}}=0.0156$ & $\mathrm{R}_{\mathrm{wp}}=0.0048, \mathrm{R}_{\mathrm{p}}=0.0094$ \\
\hline $\mathrm{R}_{\mathrm{ex}}=0.0072, \mathrm{R}_{\mathrm{F}} 2=0.0713$ & $\mathrm{R}_{\mathrm{ex}}=0.0049, \mathrm{R}_{\mathrm{F}} 2=0.0563$ \\
\hline Neutron (low angle) & Neutron (low angle) \\
\hline $\mathrm{R}_{\mathrm{wp}}=0.0240, \mathrm{R}_{\mathrm{p}}=0.0249$ & $\mathrm{R}_{\mathrm{wp}}=0.0137, \mathrm{R}_{\mathrm{p}}=0.0133$, \\
\hline $\mathrm{R}_{\mathrm{ex}}=0.0269, \mathrm{R}_{\mathrm{F}} 2=0.1067$ & $\mathrm{R}_{\mathrm{ex}}=0.0136, \mathrm{R}_{\mathrm{F}} 2=0.0757$ \\
\hline X-ray & X-ray \\
\hline $\mathrm{R}_{\mathrm{wp}}=0.0455, \mathrm{R}_{\mathrm{p}}=0.0304$ & $\mathrm{R}_{\mathrm{wp}}=0.0507, \mathrm{R}_{\mathrm{p}}=0.0327$ \\
\hline $\mathrm{R}_{\mathrm{ex}}=0.0207, \mathrm{R}_{\mathrm{F}} 2=0.0869$ & $\mathrm{R}_{\mathrm{ex}}=0.0247, \mathrm{R}_{\mathrm{F}} 2=0.1241$ \\
\hline Totals & Totals \\
\hline $\mathrm{R}_{\mathrm{wp}}=0.0200, \mathrm{R}_{\mathrm{p}}=0.0302$ & $\mathrm{R}_{\mathrm{wp}}=0.0137, \mathrm{R}_{\mathrm{p}}=0.0321$ \\
\hline $\begin{array}{l}\chi^{2}=2.619 \\
124\end{array}$ & $\begin{array}{l}\chi^{2}=2.466 \\
117\end{array}$ \\
\hline $\begin{array}{l}3822 \text { (Neutron,back- } \\
\text { scattering) }\end{array}$ & $\begin{array}{l}3511 \text { (Neutron,back- } \\
\text { scattering) }\end{array}$ \\
\hline 4641 (Neuton,low-angle) & 4140 (Neuton,low-angle) \\
\hline 6282 (X-ray) & 6282 (X-ray) \\
\hline 98 (Neutron,back-scattering) & 55 (Neutron,back-scattering) \\
\hline 56 (Neuton,low-angle) & 22 (Neuton,low-angle) \\
\hline 32 (X-ray) & 32 (X-ray) \\
\hline
\end{tabular}


Table 3

(a) Final refined parameters and (b) significant contact distances $(\AA)$ in $\mathrm{Bi}_{3} \mathrm{Nb}_{1-x} \mathrm{Yb}_{x} \mathrm{O}_{7-x}$ at room temperature and $800^{\circ} \mathrm{C}$

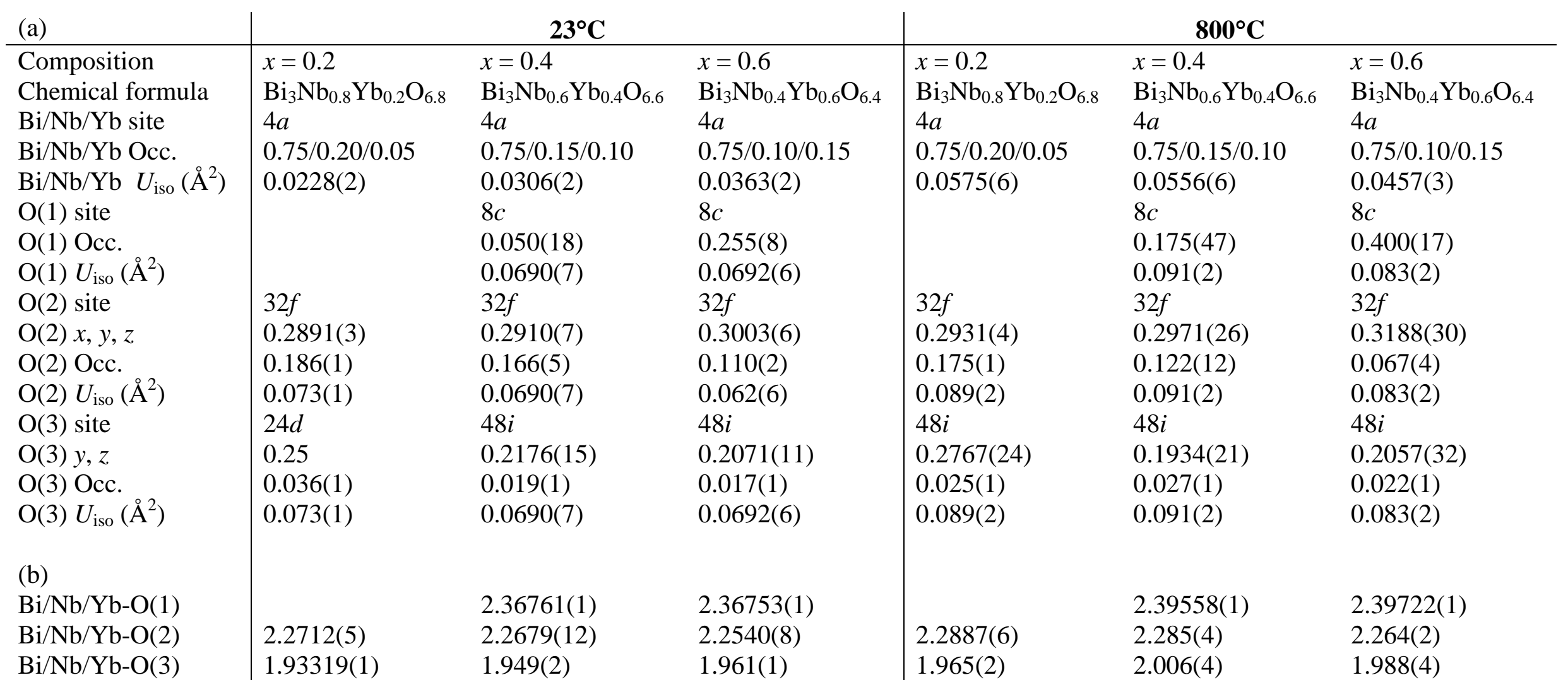




\section{Table 4}

Cation coordination numbers $(\mathrm{CN})$ and $\mathrm{M}-\mathrm{O}$ bond lengths from

RMC models of $\mathrm{Bi}_{3} \mathrm{Nb}_{0.4} \mathrm{Yb}_{0.6} \mathrm{O}_{6.4}$ at room temperature using sum of ionic radii (mean M-O distance) and integration of $g_{\mathrm{MO}}(r)$ to first minimum (modal M-O distance) approaches. Standard deviations based on values from 10 parallel runs are given in parentheses.

\begin{tabular}{|c|c|c|c|c|c|}
\hline \multirow{2}{*}{ Cation } & \multicolumn{2}{|c|}{ Ionic radii approach } & \multicolumn{3}{|c|}{$\begin{array}{c}\text { Integration to the first minimum of } \\
g_{\mathrm{MO}}(r) \text { approach }\end{array}$} \\
\hline & $\mathrm{CN}$ & $\mathrm{M}-\mathrm{O}(\AA)$ & $\mathrm{CN}$ & $\mathrm{M}-\mathrm{O}(\AA)$ & Max. $r(\AA)$ \\
\hline $\mathrm{Bi}^{3+}$ & $4.223(4)$ & $2.2604(4)$ & $4.651(6)$ & $2.232(3)$ & 2.66 \\
\hline $\mathrm{Nb}^{5+}$ & $3.46(2)$ & $1.9745(3)$ & $5.08(2)$ & $2.170(2)$ & 2.40 \\
\hline $\mathrm{Yb}^{3+}$ & $4.11(2)$ & $2.1630(8)$ & $4.89(1)$ & $2.100(3)$ & 2.64 \\
\hline $\mathrm{Av} . \mathrm{M}$ & 4.13 & 2.217 & 4.73 & 2.21 & \\
\hline
\end{tabular}

\section{Table 5}

Theoretical and observed (from Rietveld analysis and RMC calculations) tetrahedral site vacancy concentrations per fluorite cell in $\mathrm{Bi}_{3} \mathrm{Nb}_{0.4} \mathbf{Y b}_{0.6} \mathbf{O}_{6.4}$ ( (Theor (1) $=$ Theoretical Model 1: occupation only of tetrahedral site $(8 c+32 f)$; Theor $(2)=$ Theoretical Model 2: occupation of tetrahedral site and interstitial $48 i$ site)

\begin{tabular}{|c|c|c|c|c|c|}
\hline $\boldsymbol{x}$ & Temp $\left({ }^{\circ} \mathbf{C}\right)$ & Theor (1) & Theor (2) & Rietveld & RMC \\
\hline \multirow{2}{*}{$\mathbf{0 . 2}$} & 23 & 1.20 & 2.20 & 2.05 & \\
\cline { 2 - 6 } & 800 & 1.20 & 2.20 & 2.40 & \\
\hline \multirow{2}{*}{$\mathbf{0 . 4}$} & 23 & 1.40 & 2.40 & 2.29 & \\
\cline { 2 - 6 } & 800 & 1.40 & 2.40 & 2.70 & \\
\hline \multirow{2}{*}{$\mathbf{0 . 6}$} & 23 & 1.60 & 2.60 & 2.44 & 2.79 \\
\cline { 2 - 6 } & 800 & 1.60 & 2.60 & 2.64 & \\
\hline
\end{tabular}


Table 6.

Activation energy at low temperatures $\left(\Delta \mathrm{E}_{\mathrm{LT}}\right)$ and at high temperatures $\left(\Delta \mathrm{E}_{\mathrm{HT}}\right)$ and conductivity at $300^{\circ} \mathrm{C}\left(\sigma_{300}\right)$ and $800^{\circ} \mathrm{C}\left(\sigma_{800}\right)$ for $\mathrm{Bi}_{3} \mathrm{Nb}_{1-x} \mathrm{Yb}_{x} \mathrm{O}_{7-x}$.

Values correspond to second cooling run.

\begin{tabular}{|c|c|c|c|c|}
\hline$x$ & $\sigma_{300} / \mathrm{S} \mathrm{cm}^{-1}$ & $\sigma_{800} / \mathrm{S} \mathrm{cm}^{-1}$ & $\Delta E_{\mathrm{LT}} / \mathrm{eV}$ & $\Delta E_{\mathrm{HT}} / \mathrm{eV}$ \\
\hline 0.2 & $2.6(8) \times 10^{-6}$ & $0.06(1)$ & $0.99(1)$ & $1.33(2)$ \\
\hline 0.4 & $7.2(8) \times 10^{-6}$ & $0.25(5)$ & $1.08(1)$ & $0.98(2)$ \\
\hline 0.6 & $2.3(2) \times 10^{-5}$ & $0.43(20)$ & $1.06(1)$ & $0.81(4)$ \\
\hline
\end{tabular}




\section{Figure Captions}

Fig.1. Fitted (a) total scattering $S(Q)$ and (b) total radial distribution $G(r)$ functions for $\mathrm{Bi}_{3} \mathrm{Nb}_{0.4} \mathrm{Yb}_{0.6} \mathrm{O}_{6.4}$ at room temperature. Observed (points), calculated (line) and difference (lower) profiles are shown.

Fig. 2. DTA thermogram for $\mathrm{Bi}_{3} \mathrm{Nb}_{0.4} \mathrm{Yb}_{0.6} \mathrm{O}_{6.4}$ on heating and cooling (as indicated by arrows).

Fig. 3. Detail of the neutron diffraction patterns for $\mathrm{Bi}_{3} \mathrm{Nb}_{1-x} \mathrm{Yb}_{x} \mathrm{O}_{7-x}$ at room temperature. Backscattered data are shown. Significant superlattice peaks are indicated by an asterisk.

Fig. 4. Oxide ion sites in $\mathrm{Bi}_{3} \mathrm{Nb}_{1-x} \mathrm{Yb}_{x} \mathrm{O}_{7-x}$. Cation and oxide positions are indicated by large and small spheres, respectively. For clarity, only one position is shown for $25 d, 32 f$ and $48 i$ sites.

Fig. 5. Variation of oxide ion site occupancies in $\mathrm{Bi}_{3} \mathrm{Nb}_{1-x} \mathrm{Yb}_{x} \mathrm{O}_{7-x}$. Values are presented as fraction of total oxide ion content. Filled and open symbols represent ambient and $800^{\circ} \mathrm{C}$ values respectively, with squares, diamonds and triangles representing $8 c, 32 f$ and $24 d / 48 i$ sites respectively. Error bars are indicated.

Fig. 6. Thermal variation of cubic lattice parameter, $a$, in $\mathrm{Bi}_{3} \mathrm{Nb}_{1-x} \mathrm{Yb}_{x} \mathrm{O}_{7-x}$, showing $x=0.2$ (squares), $x=0.4$ (filled circles) and $x=0.6$ (open circles) compositions. Error bars are smaller than symbols used.

Fig. 7. M-O pair correlation functions $g_{\mathrm{M}-\mathrm{O}}(r)$ for $\mathrm{Bi}_{3} \mathrm{Nb}_{0.4} \mathrm{Yb}_{0.6} \mathrm{O}_{6.4}$ at room temperature, showing $\mathrm{Bi}-\mathrm{O}$ (red) $\mathrm{Nb}-\mathrm{O}$ (blue) and $\mathrm{Yb}-\mathrm{O}$ (green) correlations.

Fig. 8. Example coordination polyhedra for metal atoms in $\mathrm{Bi}_{3} \mathrm{Nb}_{0.4} \mathrm{Yb}_{0.6} \mathrm{O}_{6.4}$ at room temperature, based on Rietveld and RMC analyses. (a) Bismuth four pyramidal coordination, (b) niobium distorted octahedron, (c) niobium distorted tetrahedron and (d) ytterbium distorted truncated octahedron.

Fig. 9. Arrhenius plots of total conductivity for $\mathrm{Bi}_{3} \mathrm{Nb}_{1-x} \mathrm{Yb}_{x} \mathrm{O}_{7-x}$, showing $x=0.2$ (squares), $x=0.4$ (filled circles) and $x=0.6$ (open circles) compositions. Values correspond to second cooling run.

Fig. 10. Thermal variation of ionic transference number in $\mathrm{Bi}_{3} \mathrm{Nb}_{1-x} \mathrm{Yb}_{x} \mathrm{O}_{7-x}$, showing $x=0.2$ (squares), $x=0.4$ (filled circles) and $x=0.6$ (open circles) compositions. 
(a)

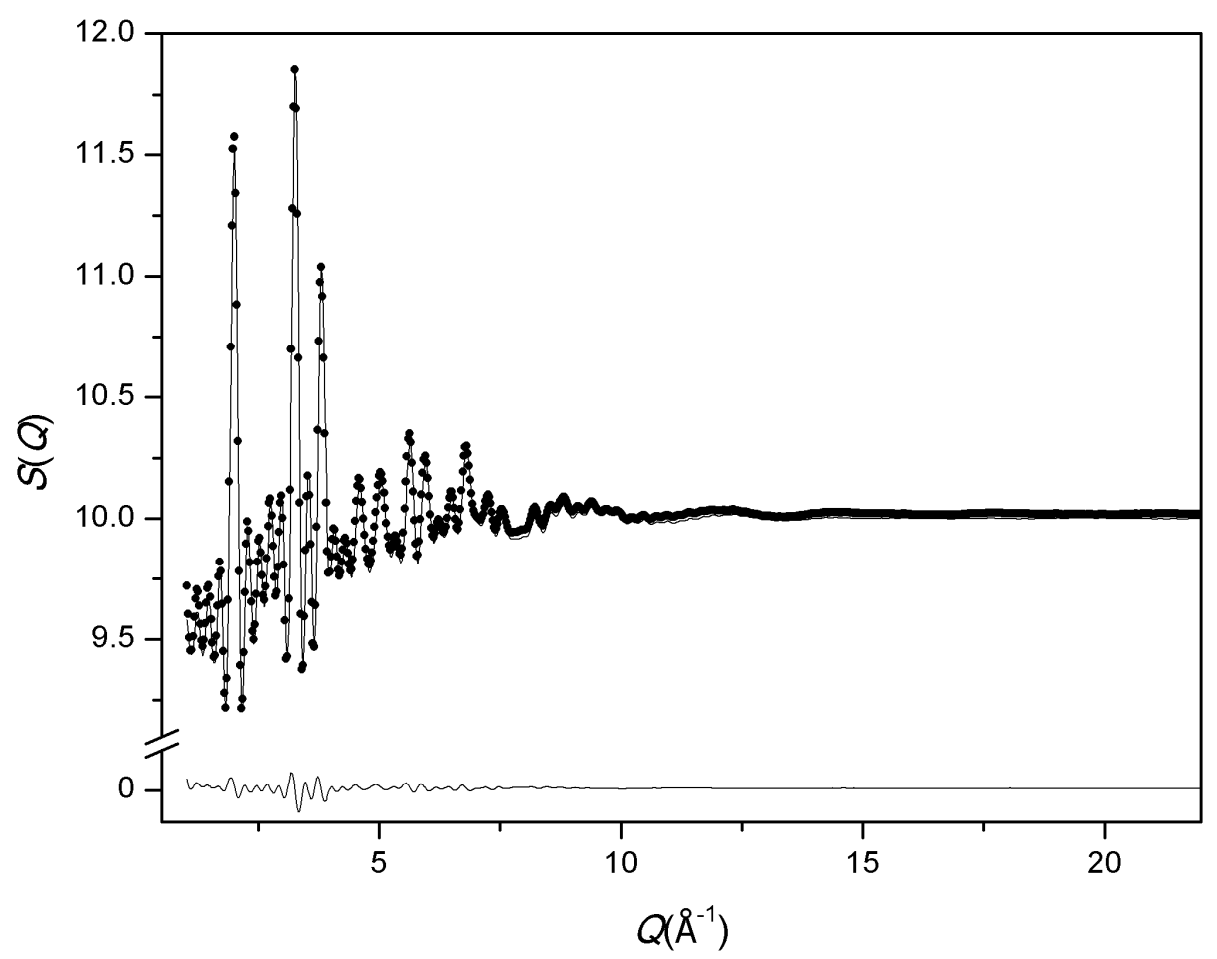

(b)

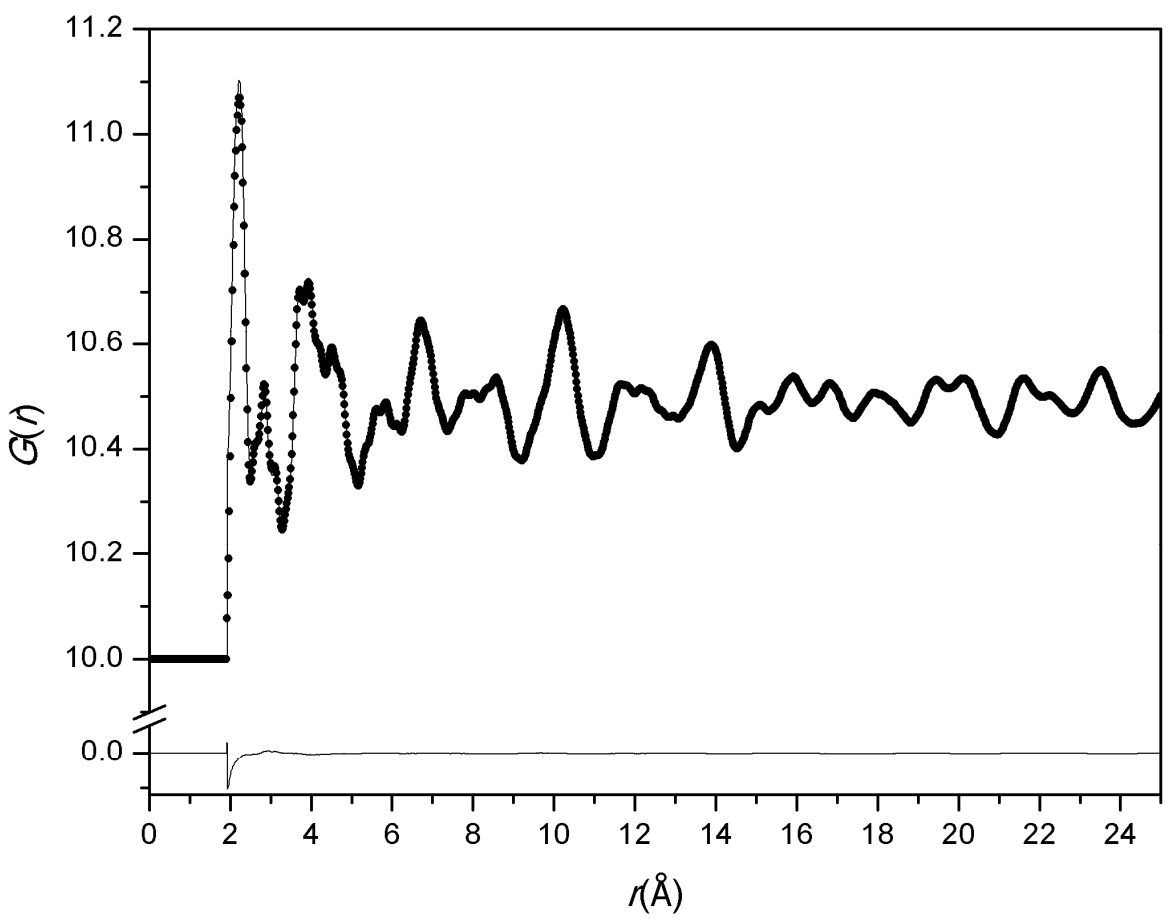

Fig.1. Fitted (a) total scattering $S(Q)$ and (b) total radial distribution $G(r)$ functions for $\mathrm{Bi}_{3} \mathrm{Nb}_{0.4} \mathrm{Yb}_{0.6} \mathrm{O}_{6.4}$ at room temperature. Observed (points), calculated (line) and difference (lower) profiles are shown. 


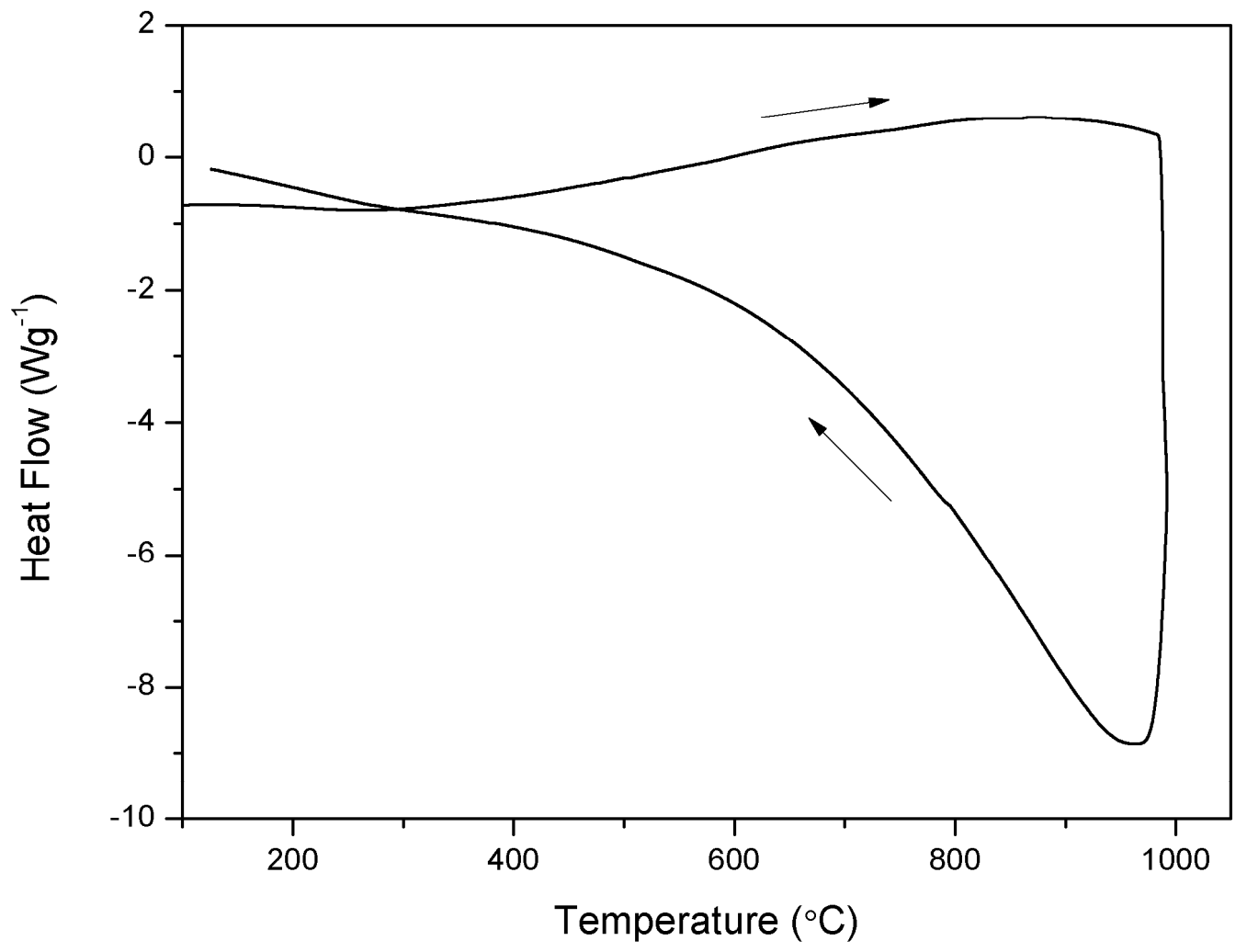

Fig. 2. DTA thermogram for $\mathrm{Bi}_{3} \mathrm{Nb}_{0.4} \mathrm{Yb}_{0.6} \mathrm{O}_{6.4}$ on heating and cooling (as indicated by arrows). 


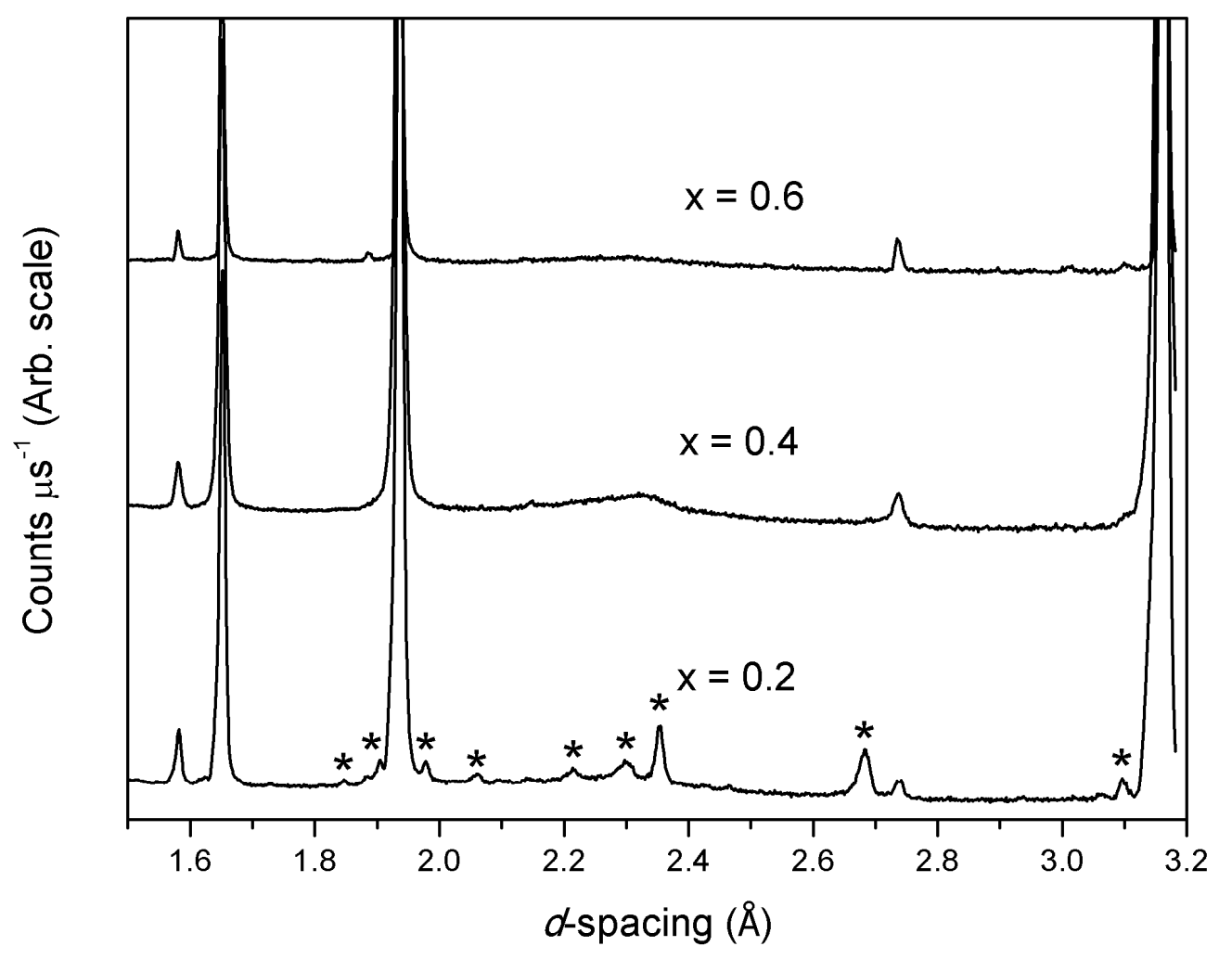

Fig. 3. Detail of the neutron diffraction patterns for $\mathrm{Bi}_{3} \mathrm{Nb}_{1-x} \mathrm{Yb}_{x} \mathrm{O}_{7-x}$ at room temperature. Backscattered data are shown. Significant superlattice peaks are indicated by an asterisk. 


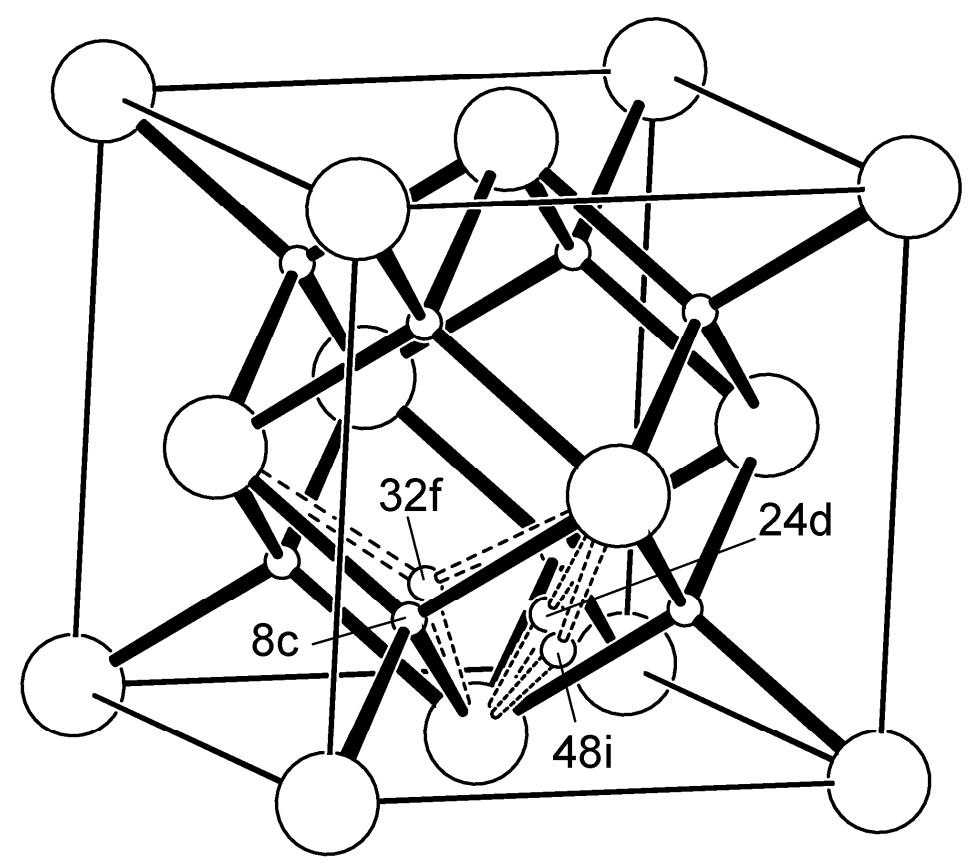

Fig. 4. Oxide ion sites in $\mathrm{Bi}_{3} \mathrm{Nb}_{1-x} \mathrm{Yb}_{x} \mathrm{O}_{7-x}$. Cation and oxide positions are indicated by large and small spheres, respectively. For clarity, only one position is shown for $25 d, 32 f$ and $48 i$ sites. 


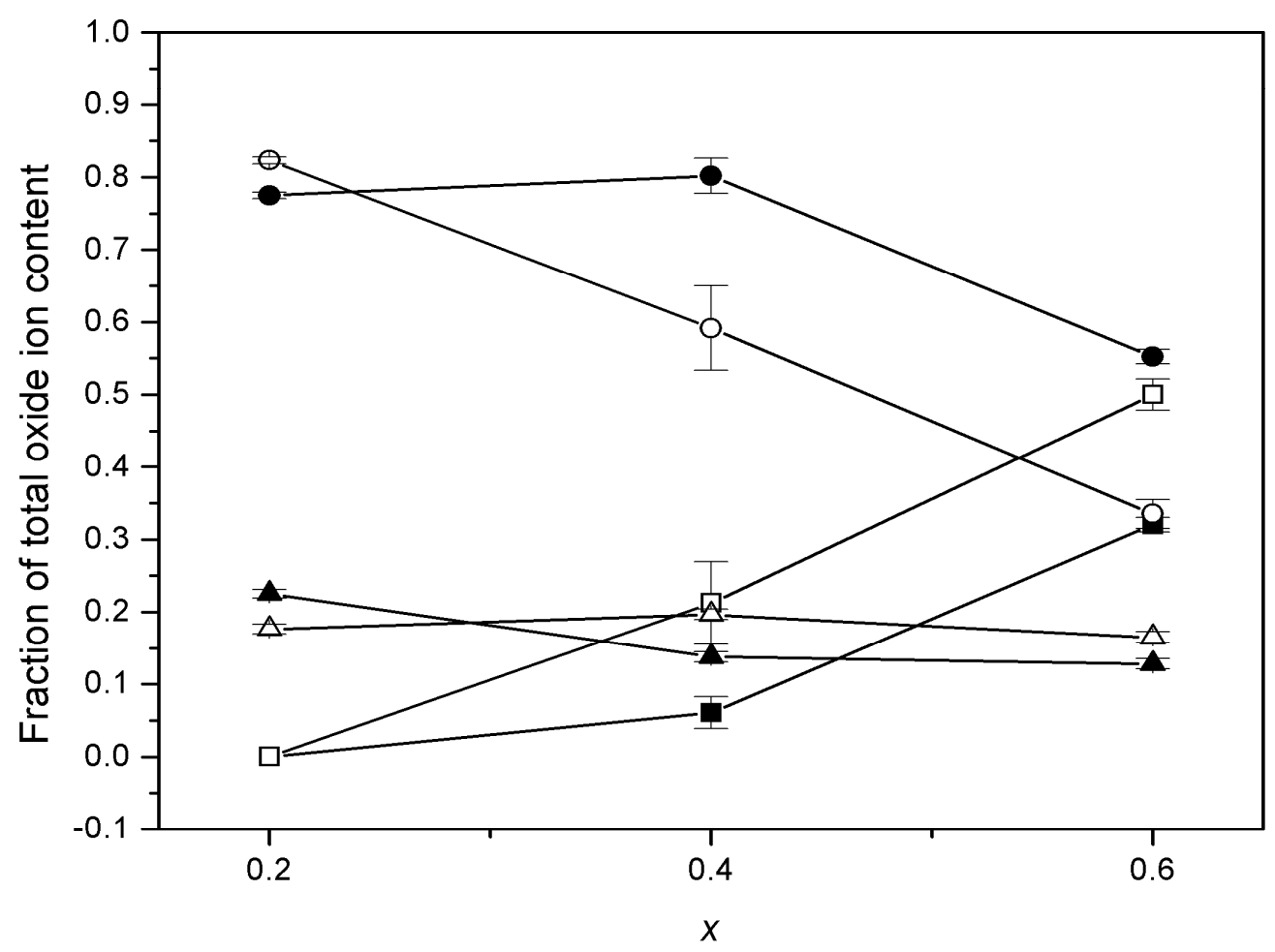

Fig. 5. Variation of oxide ion site occupancies in $\mathrm{Bi}_{3} \mathrm{Nb}_{1-x} \mathrm{Yb}_{x} \mathrm{O}_{7-x}$. Values presented as fraction of total oxide ion content. Filled and open symbols represent ambient and $800^{\circ} \mathrm{C}$ values respectively, with squares, circles and triangles representing $8 c, 32 f$ and $48 i$ sites respectively. Error bars are indicated. 


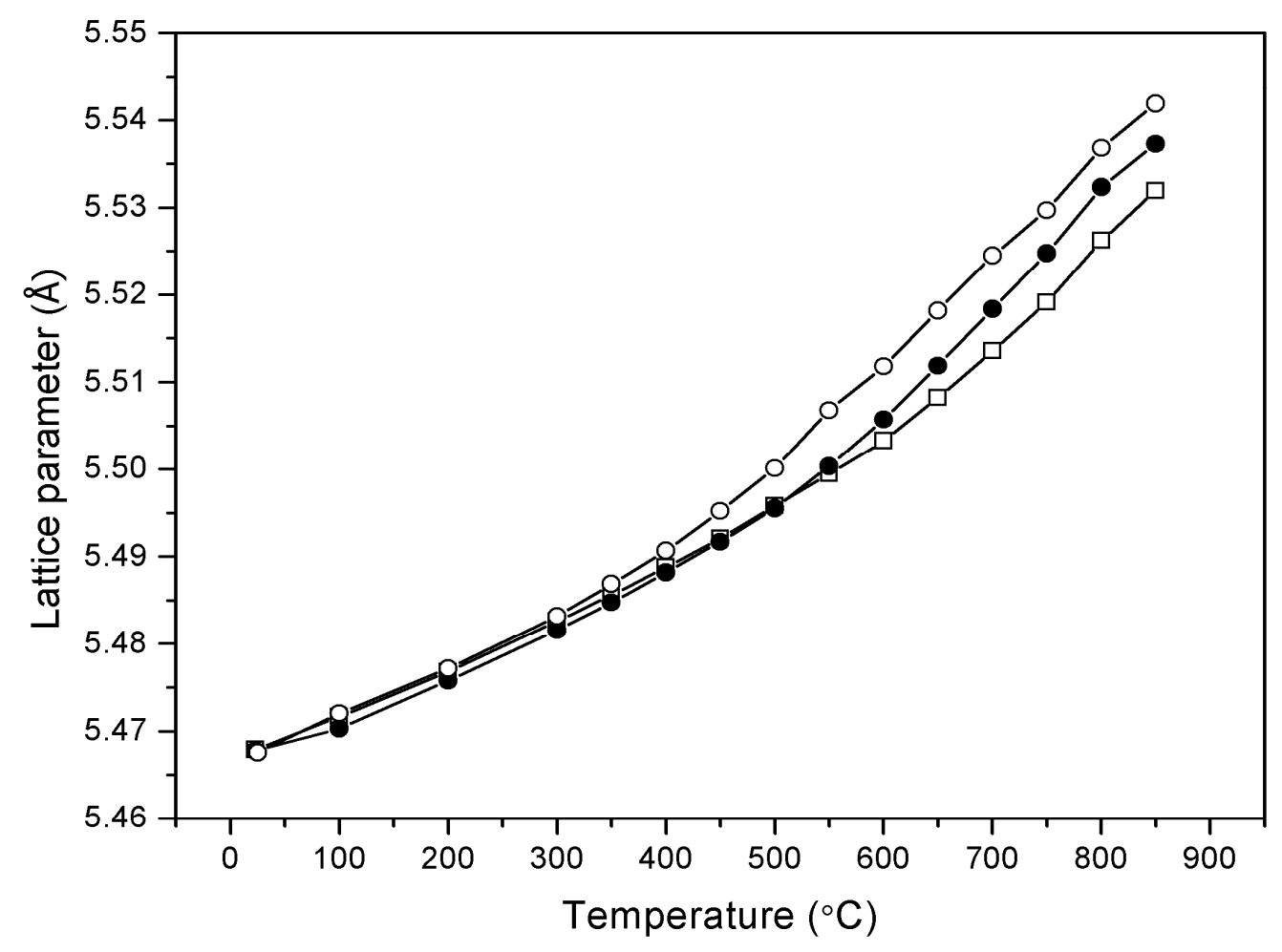

Fig. 6. Thermal variation of cubic lattice parameter, $a$, in $\mathrm{Bi}_{3} \mathrm{Nb}_{1-x} \mathrm{Yb}_{x} \mathrm{O}_{7-x}$, showing $x=0.2$ (squares), $x=0.4$ (filled circles) and $x=0.6$ (open circles) compositions. Error bars are smaller than symbols used. 


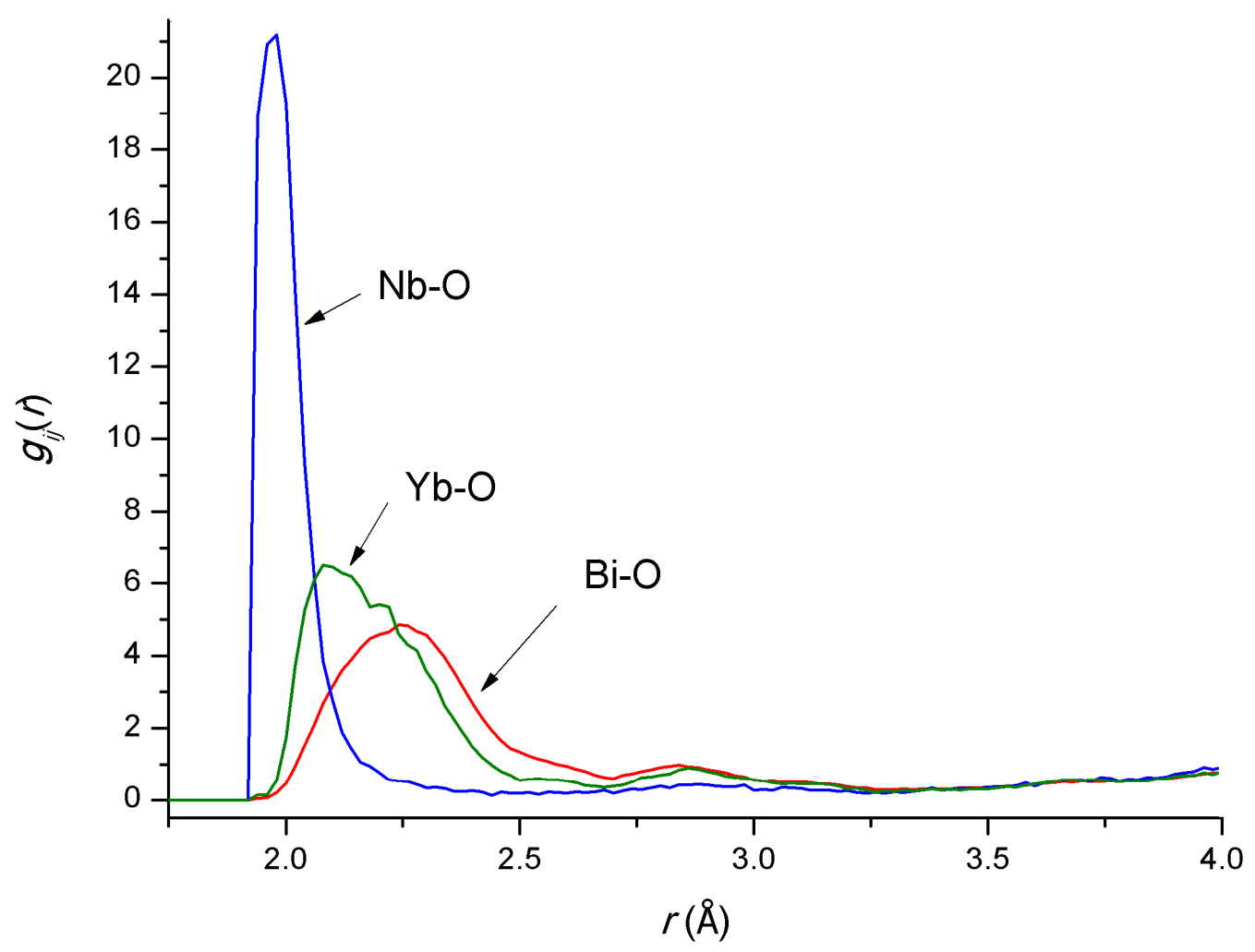

Fig. 7. M-O pair correlation functions $g_{\mathrm{M}-\mathrm{O}}(r)$ for $\mathrm{Bi}_{3} \mathrm{Nb}_{0.4} \mathrm{Yb}_{0.6} \mathrm{O}_{6.4}$ at room temperature, showing $\mathrm{Bi}-\mathrm{O}$ (red) $\mathrm{Nb}-\mathrm{O}$ (blue) and $\mathrm{Yb}-\mathrm{O}$ (green) correlations. 
(a)

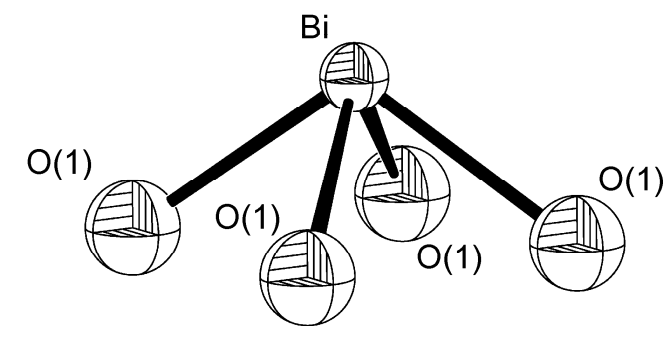

(c)

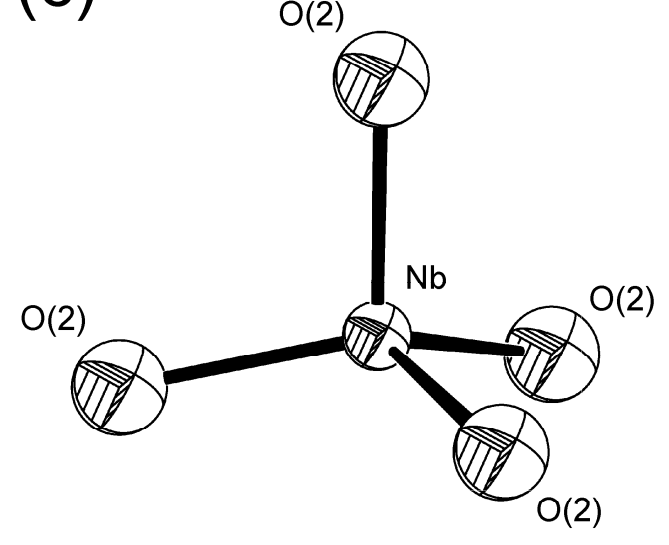

(b)

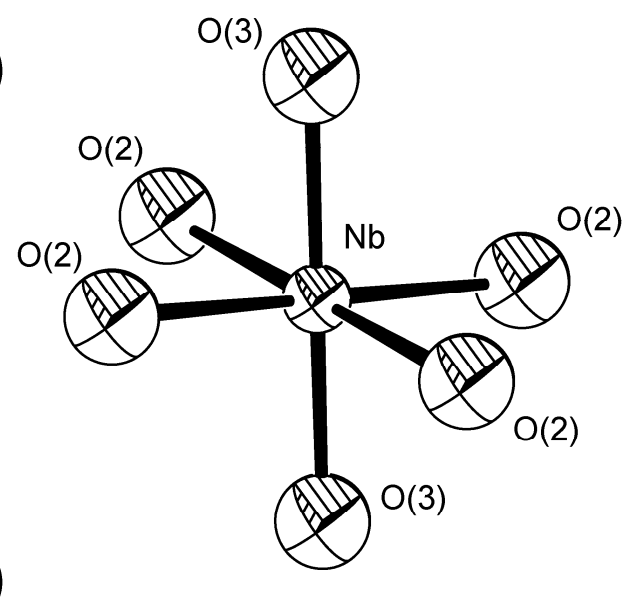

(d)

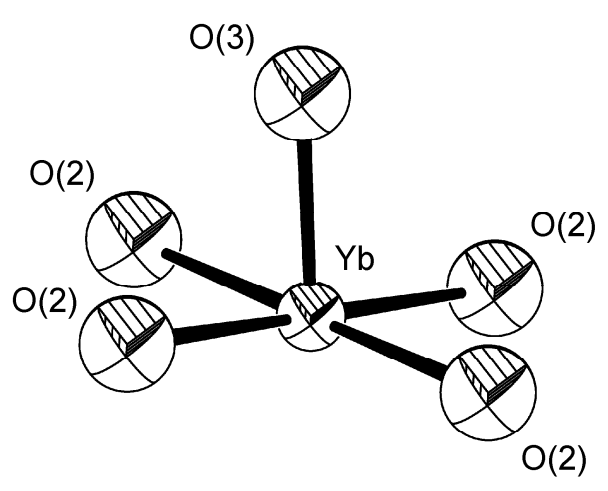

Fig. 8. Example coordination polyhedra for metal atoms in $\mathrm{Bi}_{3} \mathrm{Nb}_{0.4} \mathrm{Yb}_{0.6} \mathrm{O}_{6.4}$ at room temperature, based on Rietveld and RMC analyses. (a) Bismuth four pyramidal coordination, (b) niobium distorted octahedron, (c) niobium distorted tetrahedron and (d) ytterbium distorted truncated octahedron. 


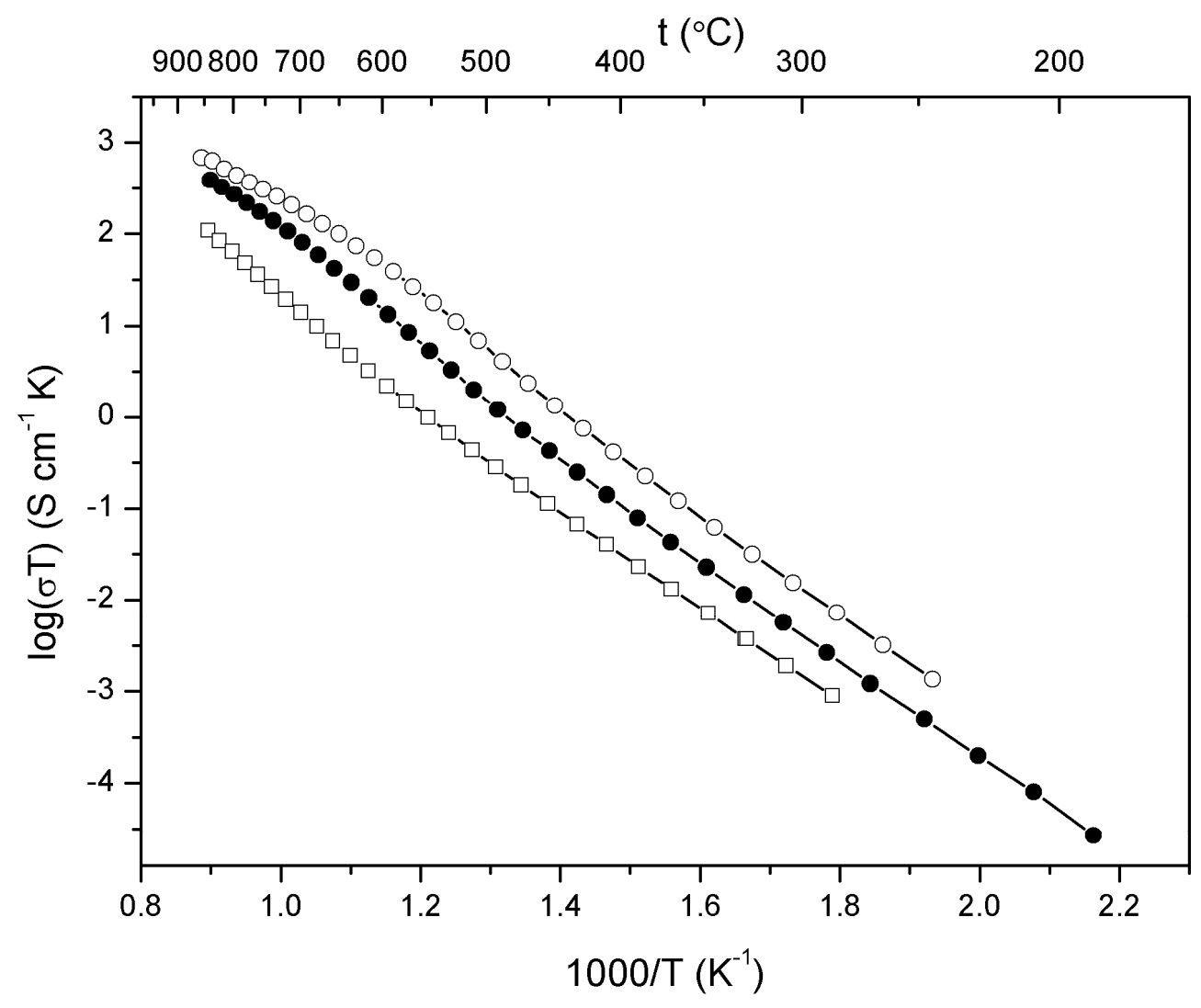

Fig. 9. Arrhenius plots of total conductivity for $\mathrm{Bi}_{3} \mathrm{Nb}_{1-x} \mathrm{Yb}_{x} \mathrm{O}_{7-x}$, showing $x=0.2$ (squares), $x=0.4$ (filled circles) and $x=0.6$ (open circles) compositions. Values correspond to second cooling run. 


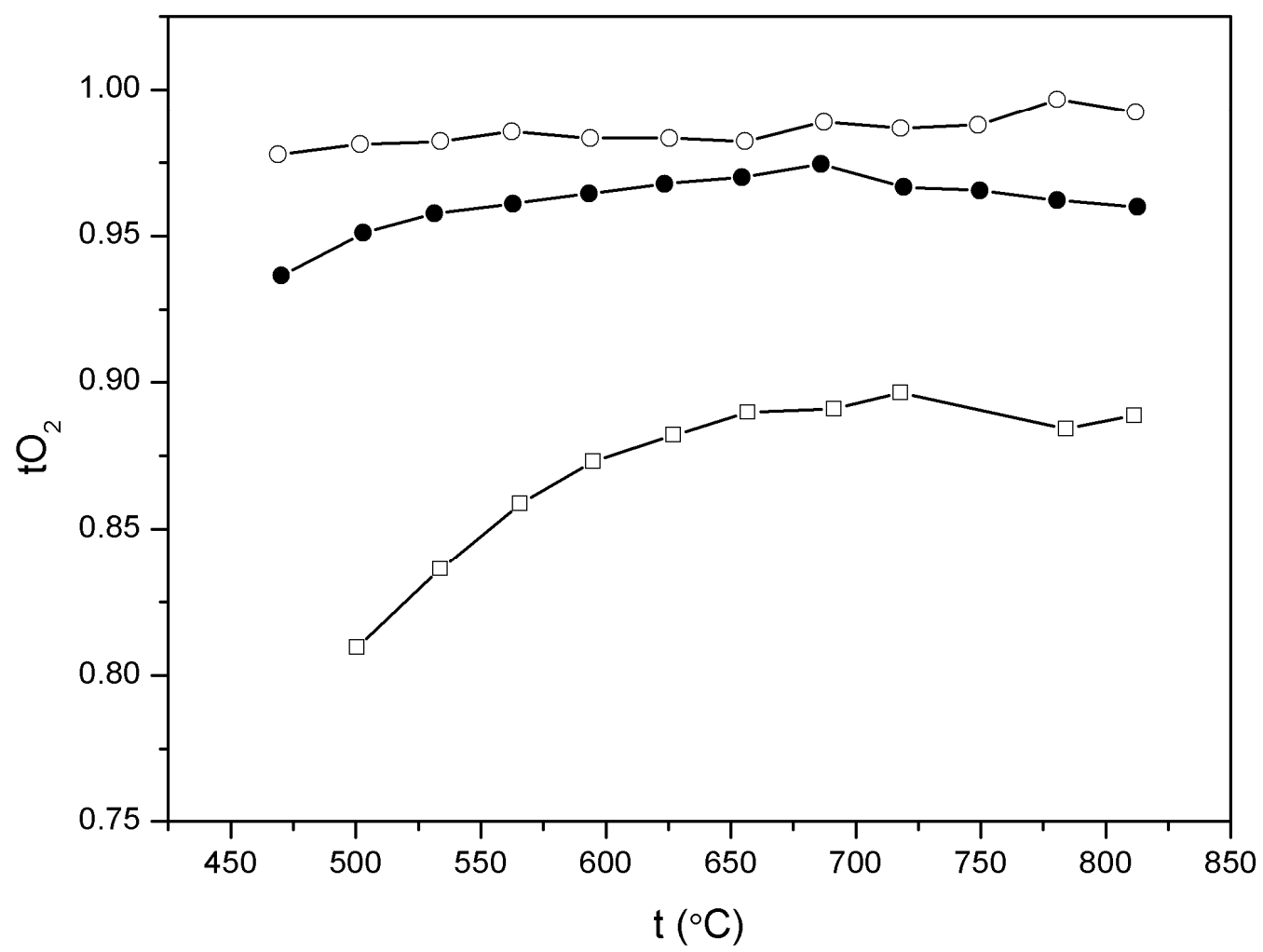

Fig. 10. Thermal variation of ionic transference number in $\mathrm{Bi}_{3} \mathrm{Nb}_{1-x} \mathrm{Yb}_{x} \mathrm{O}_{7-x}$, showing $x=0.2$ (squares), $x=0.4$ (filled circles) and $x=0.6$ (open circles) compositions. 


\section{Supplementary information}

(a)

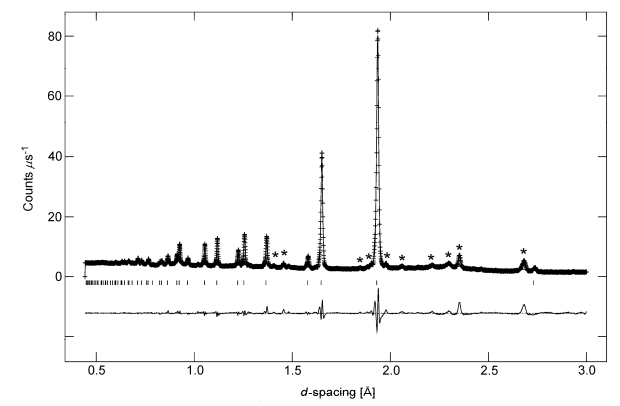

(b)

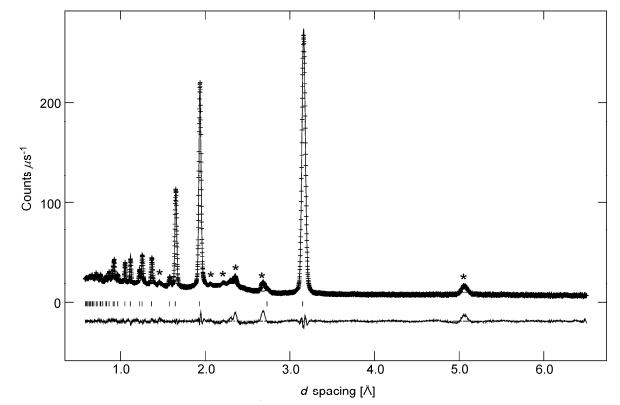

(c)

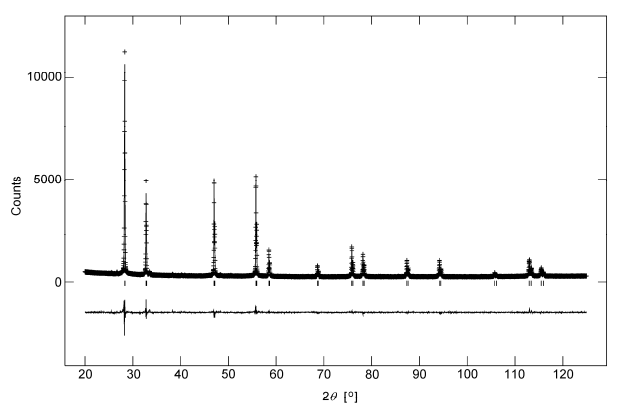

(d)

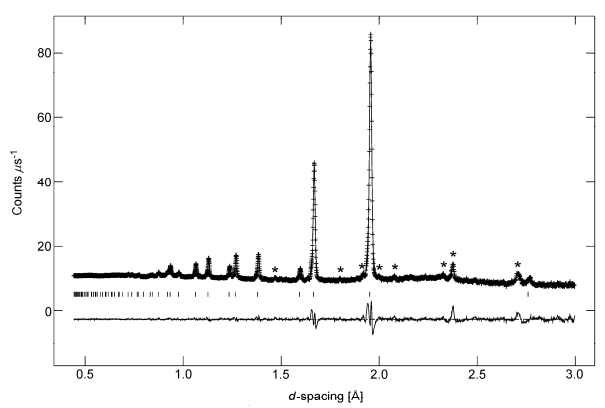

(e)

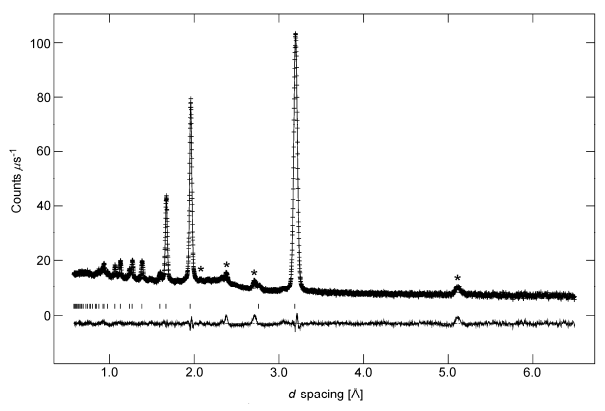

(f)

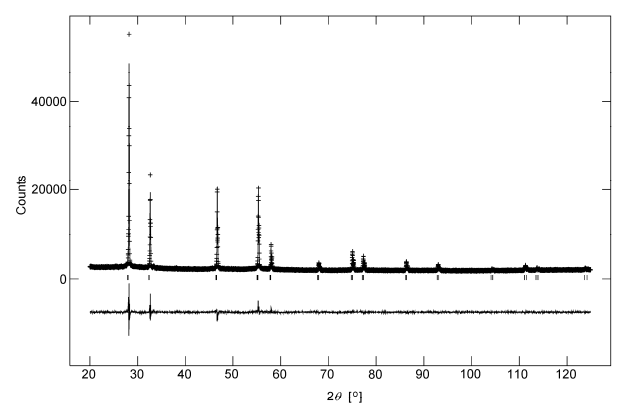

Fig. S1. Diffraction profiles for $\mathrm{Bi}_{3} \mathrm{Nb}_{0.8} \mathrm{Yb}_{0.2} \mathrm{O}_{6.8}$ at room temperature (a) to (c) and $800^{\circ} \mathrm{C}$ (d) to (f), fitted by Rietveld analysis, showing neutron back scattering (a) and (d), neutron low angle (b) and (e) and X-ray (c) and (f) data. Observed (+ symbols), calculated (line) and difference (lower) profiles are shown, with reflection positions indicated by markers. Significant superlattice peaks are indicated by an asterisk. 
(a)

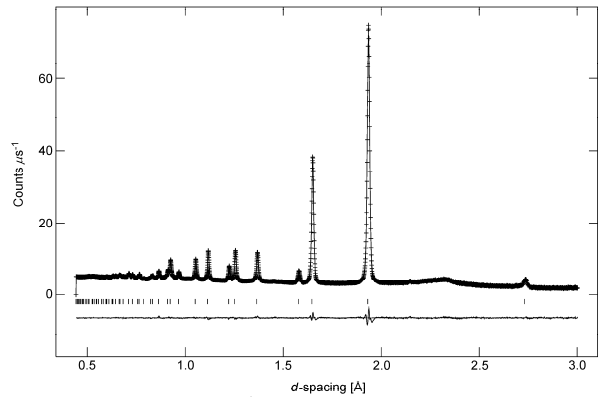

(b)

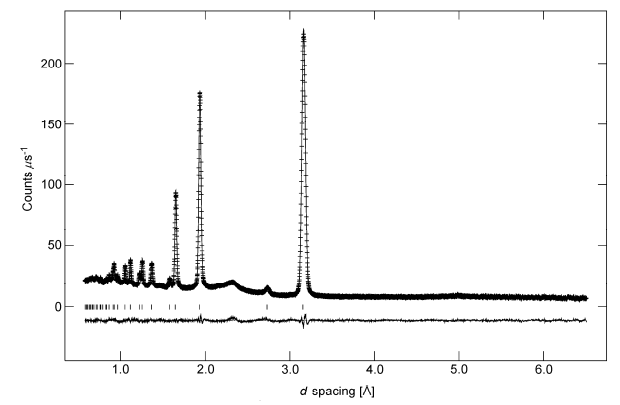

(c)

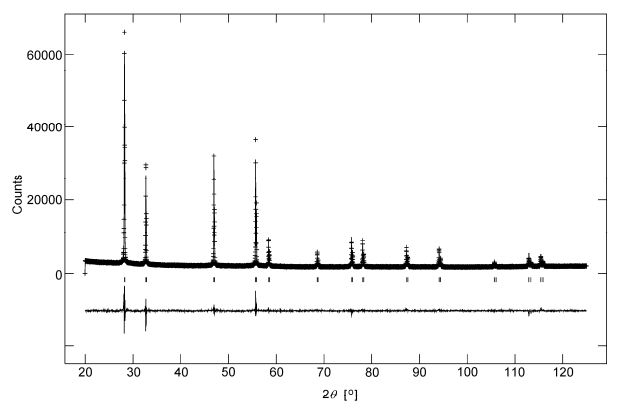

(d)

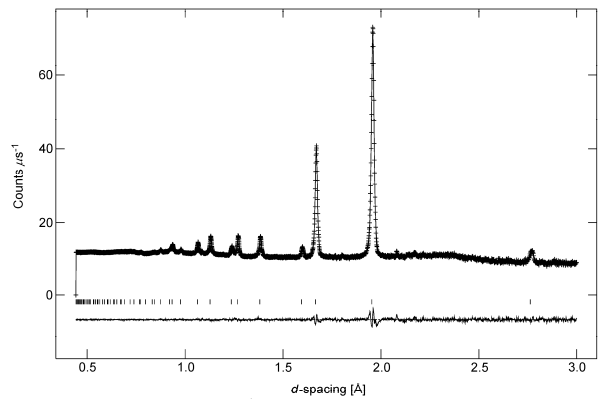

(e)

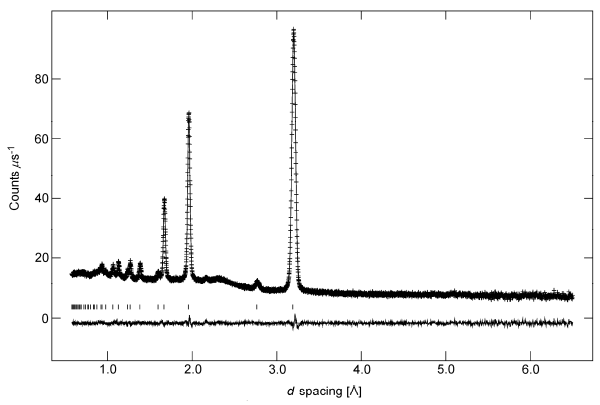

(f)

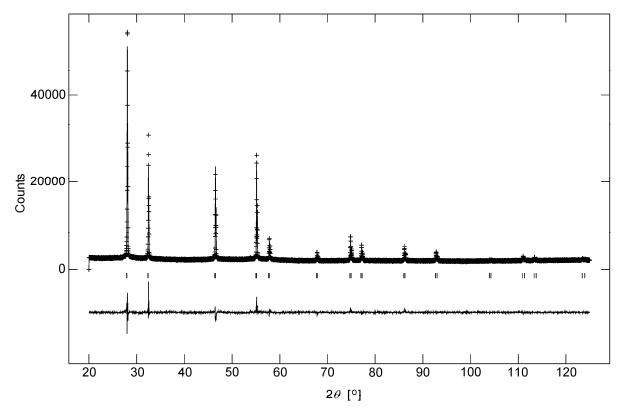

Fig. S2. Diffraction profiles for $\mathrm{Bi}_{3} \mathrm{Nb}_{0.6} \mathrm{Yb}_{0.4} \mathrm{O}_{6.6}$ at room temperature (a) to (c) and $800^{\circ} \mathrm{C}$ (d) to (f), fitted by Rietveld analysis, showing neutron back scattering (a) and (d), neutron low angle (b) and (e) and X-ray (c) and (f) data. Observed (+ symbols), calculated (line) and difference (lower) profiles are shown, with reflection positions indicated by markers. 
(a)

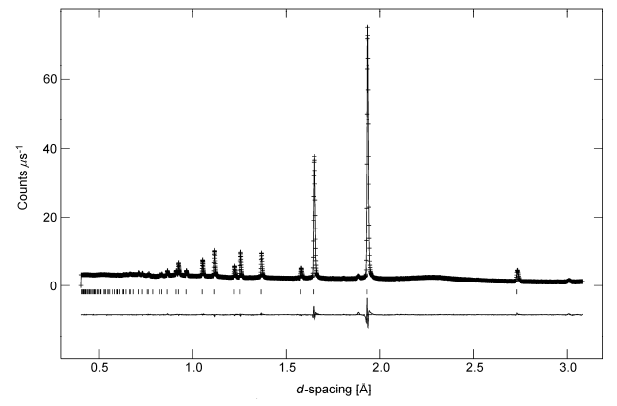

(b)

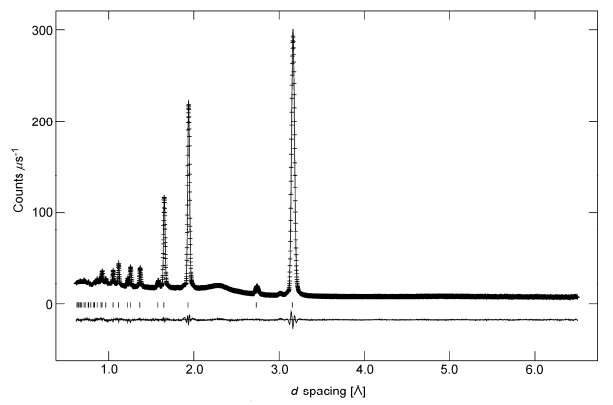

(c)

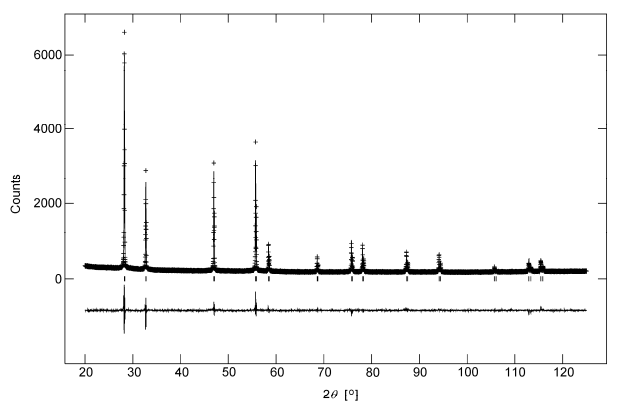

(d)

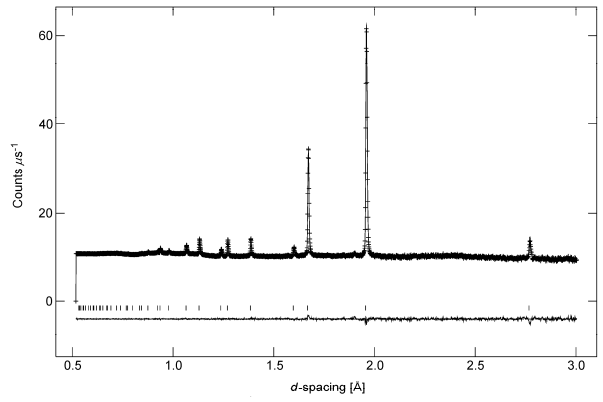

(e)

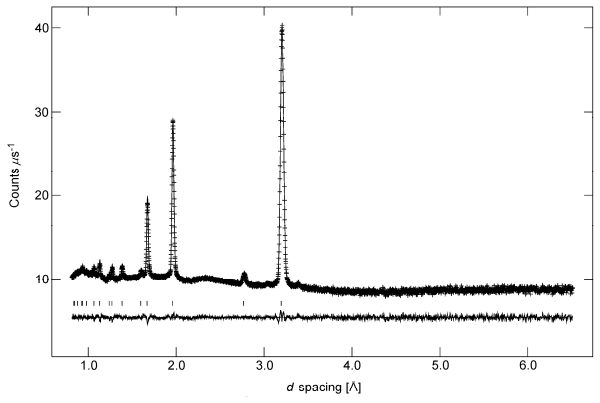

(f)

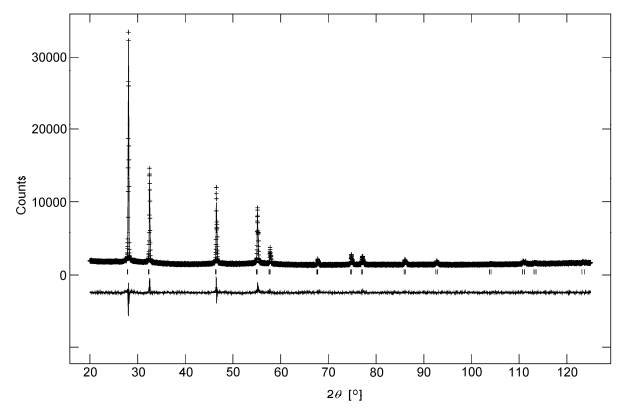

Fig. S3. Diffraction profiles for $\mathrm{Bi}_{3} \mathrm{Nb}_{0.4} \mathrm{Yb}_{0.6} \mathrm{O}_{6.4}$ at room temperature (a) to (c) and $800^{\circ} \mathrm{C}$ (d) to (f), fitted by Rietveld analysis, showing neutron back scattering (a) and (d), neutron low angle (b) and (e) and X-ray (c) and (f) data. Observed (+ symbols), calculated (line) and difference (lower) profiles are shown, with reflection positions indicated by markers. 